\title{
LA CERÁMICA PINTADA ROMANA DE TRADICIÓN INDÍGENA EN EL TERRITORIO DE EXTREMADURA
}

\author{
THE ROMAN PAINTED POTTERY OF INDIGENOUS TRADITION \\ IN THE TERRITORY OF EXTREMADURA
}

\author{
MACARENA BUSTAMANTE-ÁLVAREZ*
}

\begin{abstract}
Resumen: Realizamos una recopilación de todas las cerámicas romanas pintadas de tradición indígena que, inéditas o no, se hayan localizado en el suelo de la actual Extremadura. El interés de este estudio radica en presentar una nueva lectura de algunas formas en clave estratigráfica, aportar ejemplos inéditos y proponer nuevos focos productivos en la zona. Aportamos un catálogo actualizado de piezas y realizamos también una aproximación cronológica a las mismas proponiendo un cuadro cronológico evolutivo de dichas formas.

Palabras clave: Cerámica, pintada, tradición indígena, $\mathrm{Au}$ gusta Emerita, Caparra, Augustobriga.
\end{abstract}

\section{INTRODUCCIÓN}

En el presente trabajo realizamos una recopilación de las piezas de "cerámica pintada romana de tradición indígena" (Abascal 1986: 22) que, inéditas y publicadas, se hayan localizado en suelo extremeño. Hay que indicar que, frente a lo que podemos creer, su número es casi anecdótico y las formas y esquemas localizados son muy restringidos. Apriorísticamente, podemos observar dos focos de consumo y posible producción en este marco geográfico. Uno está en el norte, donde

\footnotetext{
* Programa Juan de la Cierva Ministerio de Economía y Competitividad. Departamento de Historia y Teoría del Arte. Facultad de Filosofía y Letras. Universidad Autónoma de Madrid. C/ Francisco
}

\begin{abstract}
We make a compilation of all the Roman pottery painted of indigenous tradition, published or not, which have been located on the current Extremadura. The interest of this study is to present a new interpretation of some of them with stratigraphy. Also we provide new unpublished examples and propose new productive centers in this area. We profile an updated catalogue of the shapes and also we point out a diacronic approach to this production.

Key words: Pottery, painted, indigenous tradition, Augusta Emerita, Caparra, Augustobriga.
\end{abstract}

las producciones presentan fuertes semejanzas con los grupos determinados como "del área cultural lusitanogallega" y "Meseta Norte/tipo Clunia" (Abascal 1986: 193-194); estilos que se combinan con la aparición de un grupo productivo que denominamos "caparense". El otro grupo estaría al sur, donde la producción local lusitana se confunde con los motivos decorativos del tipo "Meseta Sur" (Abascal 1986: 89).

La razón de ser de este trabajo es intentar llenar el vacío de conocimiento que sobre este tipo cerámico tenemos en este espacio. A pesar de que las piezas no son

Tomás y Valiente, nº 1. 28049 - Madrid (España). Universidad Autónoma de Madrid. Correo-e: macarena.bustamante@uam.es, orcid. org/0000-0001-5988-6908 
muy numerosas sí presentan unos rasgos estilísticos homogéneos que nos permiten hablar de horizontes productivos cercanos.

El interés de estudios de este calibre hay que rastrearlos en los años 80 cuando el Prof. Abascal en su obra La cerámica pintada romana de tradición indígena en la Península Ibérica, además de localizar algunas piezas dispersas en suelo extremeño, planteó la posibilidad de la existencia de dos talleres en la región, uno en el norte y otro en el sur. El mismo autor centraba esta problemática en el cap. II, punto 2 en el que dedicaba un espacio, en exclusividad, al "Área Gallega y Portuguesa". Caracterizaba inicialmente este horizonte productivo extremeño como "de complejo" al plantearlo como una síntesis de varias realidades culturales (Abascal 1986: 101). Podemos decir que este trabajo viene a confirmar esta hipótesis al aportar nuevas piezas que nos hablan de complejos productivos similares.

Para hacer frente a este objetivo hemos tomado como referencia las piezas procedentes de distintas intervenciones arqueológicas acometidas por toda Extremadura, a lo que hay que añadirle un grupo de piezas depositadas en el Museo Nacional de Arte Romano que, aunque carentes de contexto, nos han permitido aumentar el elenco formal. Geográficamente, los espacios que más piezas han aportado son los municipios hispanorromanos de Cáparra, Augustobriga y la colonia de Augusta Emerita, siendo muy esporádica su aparición en ámbito rural. Esta dicotomía espacial quizás nos hable de pautas de consumo y aspectos adquisitivos del producto en este espacio.

Una de las novedades que aporta este trabajo es presentar las piezas insertas en sus contextos de aparición. Esto nos ha permitido trazar una línea diacrónica en la conformación y evolución de las formas desde el siglo I d.C. Se observa un repunte claro en época flavia, como le ocurre a la producción en general (Abascal 1986: 21-22), y una depresión hasta el siglo V d.C. momento en el cual el número de piezas se dispara y que, frente a lo que podríamos pensar, mantienen esquemas productivos y decorativos muy similares a los propiamente altoimperiales.

\section{HACIA UNA PROPUESTA TIPOLÓGICA FORMAL DE LAS PIEZAS DECORADAS}

Las casi ochenta piezas que presentamos nos permiten realizar una sucinta valoración de cuáles fueron los elementos consumidos en suelo extremeño y aproximarnos al modo productivo desarrollado. Podemos determinar la existencia de, al menos, dos focos productores, uno afincado en la capital de la Lusitania y otro que debemos ubicar en el Norte como ya había esbozado el Prof. Abascal (1986).

En ambos casos, se observa cómo la producción aparece muy diversificada, hecho que radica en lo que entendemos una libre interpretación de los motivos foráneos y en una no estandarización de la producción. Por el contrario, a medida que nos alejamos de dicho foco, se observa una mayor reiteración de formas y motivos decorativos que nos hablan de una clara esquematización de la producción.

\subsection{Caracterización de las piezas}

Genéricamente se observa cómo el conjunto de las piezas usan pastas no calcáreas evitando así los fondos blancos que pudieran mitigar el efecto de la decoración. Son seis los grupos de pastas que se observan macroscópicamente:

- Tipo A: pastas en tonos anaranjados, muy esporádicamente grisáceos y achocolatados claros. Consistencia muy amasada con barros muy depurados y limpios. Raramente presentan puntos de mica plateada de granulometría media y fina. Todos tienen un tratamiento externo muy concreto, a partir de una fina aguada espatulada levemente. Este grupo sería el más ampliamente documentado y se asimila a las producciones de la Meseta Sur.

- Tipo B: pastas poco amasadas, gruesas y muy caoliníticas. Consistencia muy pesada y fractura irregular provocada por los abultados desgrasantes que presenta, de granulometría media y alta. Podríamos indicar que estamos ante un estadio evolucionado de las pastas propias de las paredes finas emeritenses.

- Tipo C: pastas marrones oscuras, con puntos blancos y negros. Consistencia amasada y fractura con mucha arista. Podríamos indicar que estamos ante masas típicas de cerámicas comunes locales emeritenses de facies tardías. No presentan ningún tipo de preparación en su superficie para recibir la pintura, por lo que se deduce que no son piezas realizadas ex professo para ser pintadas.

- Tipo D: pasta de coloración anaranjada oscura, muy rugosa y con inclusiones esquistosas. Su fractura es muy irregular. La característica principal de este tipo es la aplicación de un recubrimiento externo blanco que hace de superficie sobre la cual reposa la decoración. 
Figura 1. Mapa con los lugares de procedencia de las piezas estudiadas $\left(\mathrm{n}^{\mathrm{o}}\right.$ 1: Mérida, $\mathrm{n}^{\mathrm{o}}$ 2: Cáparra, $\mathrm{n}^{\circ} 3$ : Augustobriga y $\mathrm{n}^{\circ}$ 4: Alconétar).

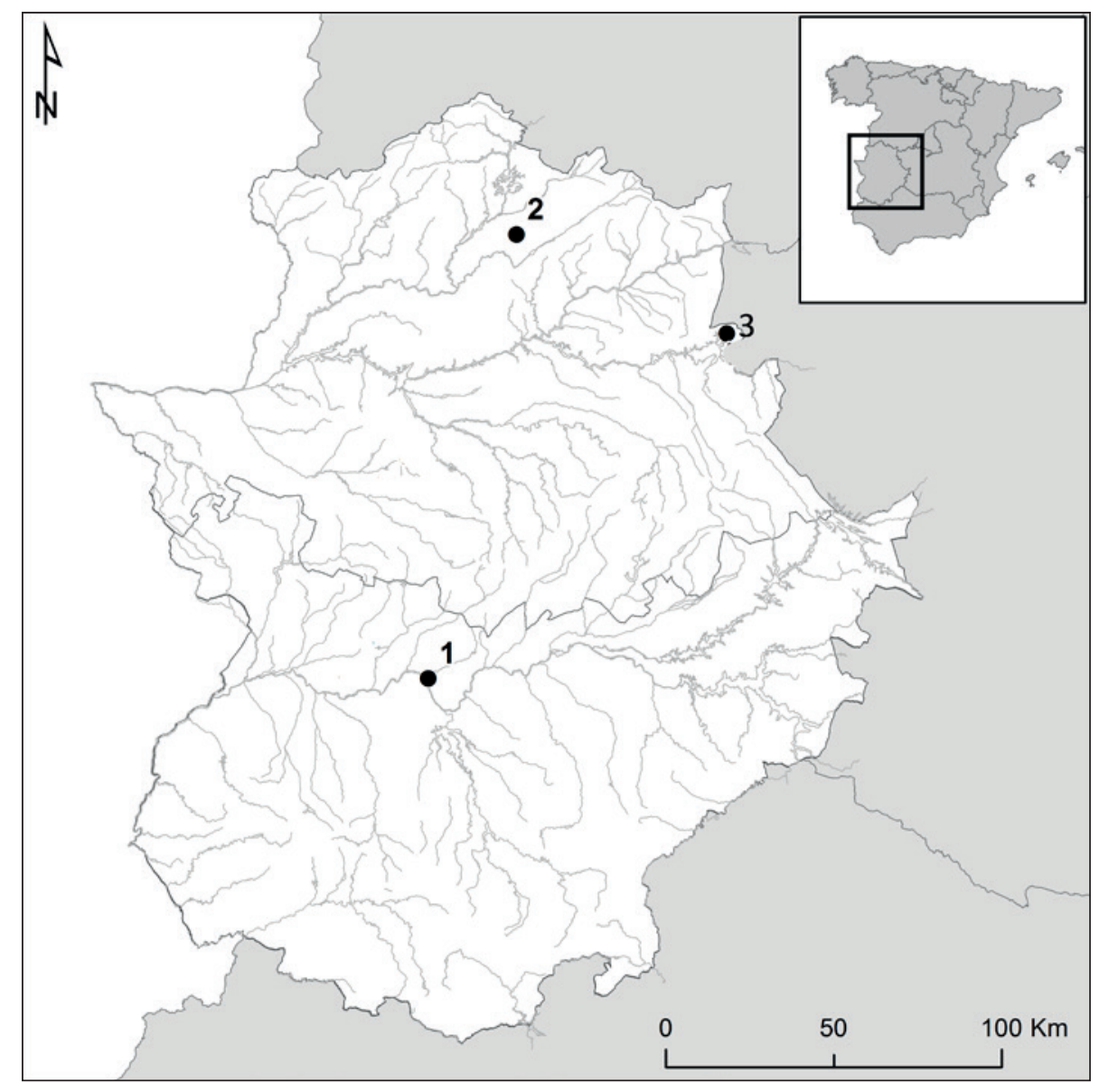

- Tipo E: pastas de tonalidad anaranjada, muy depuradas con puntos blancos y micáceos. Presentan un tratamiento espatulado. Las cocciones, como vemos en sus perfiles, son mixtas.

- Tipo F: pastas blanquecinas con algunos puntos marrones y virados verdes. Está muy depurada y amasada. En algunos casos la superficie a decorar se presenta bruñida quizás como apoyo a una mejor adherencia del pigmento.

De estos seis tipos de pastas aislados macroscópicamente, podemos indicar que el primero (tipo A) es el más extendido tanto en cantidad como en difusión geográfica. Conviene igualmente indicar que no solo se circunscriben a suelo extremeño sino que también se extienden a otros puntos de la Península Ibérica. Estas pastas están bien tipificadas, quedando insertas dentro del grupo Meseta Sur (Abascal 2008: fig. 441). Por el contrario, el último grupo, el tipo $\mathrm{F}$, lo podríamos asociar a la producción norteña o comúnmente denominada como tipo Clunia (Taracena 1931-32: 90-91 y Abascal 1986: 48-49).
Los otros grupos parecen concentrarse en los núcleos urbanos del norte, principalmente Cáparra, $A u$ gustobriga y el entorno de Alconétar y, en el sur, en la capital de la Lusitania, Augusta Emerita y su territorium, lo que nos da pie a pensar, junto con su similitud con pastas tipificadas como locales, que estamos ante un grupo producido y consumido en este espacio.

\subsection{El grupo de inspiración Meseta Sur (fig. 2-4)}

Como ya hemos dicho, las piezas localizadas pueden encuadrarse en cuatro grandes grupos productivos, el primero "Meseta Sur", el segundo "Meseta Norte/Clunia", el tercero "caparense" y el último "emeritense".

Principalmente, los ejemplos localizados en el conjunto se pueden insertar en el grupo Meseta Sur. Recordemos que éste fue delimitado por Abascal (1986: 80-81 y 89) haciendo especial referencia a los talleres 
de Segobriga y Villa de Villaverde. Dentro de la diferenciación de pastas que hemos realizado, se asimilaría al tipo A. Podemos decir que es el grupo más abundante del repertorio, fruto de la importancia de los talleres que lo reprodujeron y, sobre todo, por la ausencia de otras oficinas coetáneas que pudieran haber competido con ellos. El estudio realizado por Abascal viene a indicar que el grueso de las piezas, aunque con fuertes similitudes con las producciones de la Meseta Sur, son producidas en un taller hasta el momento no identificado en suelo extremeño (Abascal 1986: 101-102). A pesar de ello, la mayor parte de ejemplos que hemos localizado y que presentamos como inéditos sí presentan las pastas que caracterizan a esta producción, hecho que no es óbice para que no exista un taller local-regional que las produjera con fidelidad. Esta línea de trabajo sólo se podrá comprobar con hallazgos de espacios productivos.

El grueso de los ejemplares se ubica en la zona norte, sobre todo en los yacimientos de Cáparra y en el territorium de Augustobriga, diluyéndose su intensidad a medida que avanza hacia el sur, donde la producción autóctona de Augusta Emerita comienza a predominar.

Formalmente, la pieza que más se reproduce es la forma Abascal 17 (algunas piezas de este tipo fig. 2, $\mathrm{n}^{\mathrm{o}} 1,4$ o 5), un ejemplar típico de las producciones de la Meseta Sur. Al respecto, estamos ante un pequeño vaso con cuerpo troncocónico y borde de tendencia vertical. Las piezas localizadas, aunque se presentan fragmentarias, siguen el esquema genérico establecido con un diámetro oscilante entre los 7-14 cm (Abascal 1986: 107-108). Las localizadas en suelo extremeño presentan un tamaño de boca de unos 11-12 $\mathrm{cm}$. Pueden presentar asas, como en algunos de nuestros ejemplares, y una desarrollada decoración muy estandarizada con metopas delimitadas por líneas verticales y zona en reserva.

Junto a esta forma aparecen otras piezas típicas del repertorio de la zona, como las ollas globulares del tipo Abascal 18 (por ejemplo fig. 2, n⿳0 2 o 3). Estas presentan un perfil globular con tendencia en " $\mathrm{S}$ " en la zona superior. El borde puede aparecer plano con tendencia vertical y molduras en su zona externa, en algunos de los ejemplos aparece con decoración pintada geométrica en el borde. Una variante muy peculiar sería la que presenta un perfil de borde bífido, posiblemente para encastrar tapaderas, raramente documentadas en el repertorio meseteño, así como un asa lateral con sección de cinta.

Los ejemplares localizados presentan tres esquemas decorativos:
- esquema geométrico a base de líneas verticales, oblicuas o reticuladas (fig. 3, $\mathrm{n}^{\mathrm{o}} 16,21-25$ entre otros). Los colores usados para su plasmación son los tierras y rojos sangre. Su adherencia es poco consistente de ahí que, mayoritariamente, se hayan perdido quedando simples trazas difuminadas. En casi todos los ejemplares el espacio decorado está delimitado, arriba y abajo, por una línea horizontal.

- esquema de la denominada "escalera oblicua" que podemos decir que es el más común (algunos ejemplos fig. 2, $\mathrm{n}^{\mathrm{o}} 4$ y 7-8 entre otros). Este se basa en una línea oblicua que recorre la pieza lateralmente y de la que le salen unas pequeñas líneas a modo de peldaños

- esquema fitomorfo con la aparición de una rama esquemática horizontal (fig. $4, \mathrm{n}^{\mathrm{o}} 7$ ).

Las piezas que aportamos del yacimiento de Cáparra proceden, algunas, de un vertedero ubicado a las puertas de la ciudad, más concretamente de una facie activa en época flavia y antonina temprana, gracias a la cohabitación de estas con formas en sigillata hispánica del tipo Hisp. 35-36 o 37 con decoración metopada, así como de las termas de la ciudad ${ }^{1}$. Esta cronología de fines del I d.C. e inicios del II d.C. iría en consonancia con otros estudios de corte estratigráfico como el realizado en Complutum, más concretamente en un depósito cerrado (Polo 1999).

Las otras piezas procedentes de este yacimiento no presentan contexto y han sido publicadas de manera sistemática en un catálogo sobre las cerámicas del lugar sin aportar datos concretos sobre su procedencia (RíoMiranda 2012).

Por el contrario, el registro emeritense es bastante parco y únicamente hemos localizado un ejemplar en un contexto del III d.C., como demuestra su cohabitación con piezas en ARSW-C del tipo Hayes 50 así como una Hayes 16 en ARSW-A. En el vado de Alconétar también se documentaron algunas piezas de este tipo con una composición metopada y con aparente procedencia de la Meseta Sur (Abascal 1986: lám. 91, $\mathrm{n}^{0} 506$ y 508$)$.

Se observa pues, un comercio puntual con los talleres de la Meseta Sur pero con un carácter muy monótono tanto en formas como en decoración, siendo la "escalera oblicua" la más reiterada. Frente a lo que podríamos suponer, un intenso interés por reproducir

1. De esta intervención se han dado algunas notas debido a la aparición de un horno pegado a la muralla. 
estos motivos decorativos, se observa una total dejadez por parte de los talleres locales que no parecen reproducir estos esquemas básicos. Como veremos $a$ posteriori las oficinas locales son más propensas al desarrollo de franjas compositivas más libres sin esquema aparente común.

Catálogo de las piezas caracterizadas

como de la Meseta Sur I (fig. 2)

1. Borde de forma Abascal 17 con decoración de escalera oblicua en negro. Procede de Cáparra (Río-Miranda 2012: fig. 8).

2. Borde de forma Abascal 18 con decoración de escalera oblicua en negro. Procede de Cáparra (Río-Miranda 2012: fig. 21).

3. Borde de forma Abascal 18 con decoración de escalera oblicua en negro delimitada por bandas vinosas. Procede de Cáparra (Río-Miranda 2012: fig. 21).

4. Borde de forma Abascal 17 con decoración de escalera oblicua en negro. Procede de Cáparra (Río-Miranda 2012: fig. 8).

5. Borde de forma Abascal 17 con línea en negro. Procede de Cáparra (Río-Miranda 2012: fig. 8).

6. Borde de forma Abascal 17 con decoración de escalera oblicua en rojo. Procede de Cáparra (Río-Miranda 2012: fig. 5).

7. Borde de forma Abascal 17 con decoración de escalera oblicua en rojo. Procede de Cáparra (Río-Miranda 2012: fig. 4).

8. Borde de forma Abascal 17 con decoración de escalera oblicua en rojo. Procede de Cáparra (Río-Miranda 2012: fig. 1).

9. Borde de forma Abascal 17 con decoración de escalera oblicua en rojo. Procede de Cáparra (Río-Miranda 2012: fig. 3).

10. Borde de forma Abascal 17 con decoración de escalera oblicua en negro. Procede de Cáparra (Río-Miranda 2012: fig. 8).

11. Borde de forma Abascal 18 con decoración de escalera oblicua en vinoso. Procede de Cáparra (RíoMiranda 2012: fig. 9).

12. Borde de forma Abascal 18 con asa con decoración de escalera oblicua en negro. Procede de Cáparra (Río-Miranda 2012: fig. 10).

13. Borde de forma Abascal 18 con decoración de bandas blancas. Procede de Cáparra (Río-Miranda 2012: fig. 18).
14. Borde de forma Abascal 17 con decoración de escalera oblicua en marrón oscura. Procede de Cáparra (Río-Miranda 2012: fig. 2).

15. Borde de forma Abascal 18 con decoración de línea roja bajo el borde. En la zona superior del borde líneas oblicuas. Procede de Cáparra (Río-Miranda 2012: fig. 11).

16. Borde de forma Abascal 18 con decoración de línea roja bajo el borde. Procede de Cáparra (Río-Miranda 2012: fig. 12).

17. Borde de forma Abascal 17 con decoración de escalera oblicua en negro. Procede de Cáparra (Río-Miranda 2012: fig. 8).

18. Borde de forma Abascal 17 con decoración de escalera oblicua en rojo. Procede de Cáparra (Río-Miranda 2012: fig. 3).

19. Galbo de cerámica pintada con decoración de líneas oblicuas delimitadas por dos líneas simples. Procede de Cáparra (Río-Miranda 2012: fig. 17/4)

20. Galbo de cerámica pintada con decoración de líneas oblicuas delimitadas por dos líneas simples. Procede de Cáparra (Río-Miranda 2012: fig. 17/4).

21. Galbo de forma Abascal 17 con decoración de escalera oblicua en negro. Procede de Cáparra (Río-Miranda 2012: fig. 17/1).

22. Galbo de cerámica pintada con decoración a línea simple que enmarca una línea de puntos. Procede de Cáparra (Río-Miranda 2012: fig. 17/2).

23. Galbo de forma Abascal 17 con decoración de escalera oblicua en rojo y marrón oscuro. Procede de Cáparra (Río-Miranda 2012: fig. 8).

24. Borde de forma Abascal 17 con decoración de escalera oblicua en vinoso. Procede de Cáparra (RíoMiranda 2012: fig. 8).

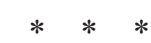

Catálogo de las piezas caracterizadas como de la Meseta Sur II (fig. 3)

1. Borde de Forma 7 con escalera oblicua de color marrón. Procede de las termas de Cáparra (Inédito)².

2. Borde de Forma 7 con escalera oblicua de color vinoso. Procede de las termas de Cáparra (Inédito).

3. Borde de Forma 7 con escalera oblicua de color vinoso. Procede de las termas de Cáparra (Inédito).

2. Todas las piezas inéditas de Cáparra se localizan actualmente en el Museo Arqueológico de Cáceres. 
4. Borde de Forma 7 con escalera oblicua de color vinoso. Procede de las termas de Cáparra (Inédito).

5. Borde de Forma 7 con escalera oblicua de color vinoso. Procede de las termas de Cáparra (Inédito).

6. Borde de variante Forma 7 con escalera oblicua de color vinoso. Procede de Mérida (Abascal 1986: 386).

7. Borde de Forma 7 con escalera oblicua de color vinoso. Procede de las termas de Cáparra (Inédito).

8. Borde de Forma 7 con representación esquemática del árbol de la vida de color vinoso. Procede de las termas de Cáparra (Inédito).

9. Galbo con decoración geométrica de coloración marronácea. Procede de las termas de Cáparra (Inédito).

10. Galbo con decoración geométrica de coloración marronácea. Procede de Alconétar (Abascal 1986: lám. 91, nº 508).

11. Galbo con decoración de escalera oblicua de coloración marronácea. Procede de las termas de Cáparra (Inédito).

12. Borde de Forma 7 con escalera oblicua de color vinoso. Procede de las termas de Cáparra (Inédito).

13. Galbo de Forma 7 con representación esquemática del árbol de la vida de color vinoso. Procede de las termas Cáparra (Inédito).

14. Galbo con decoración geométrica de coloración marronácea. Procede de las termas de Cáparra (Inédito).

15. Galbo con decoración geométrica de coloración marronácea. Procede de las termas de Cáparra (Inédito).

16. Borde de Forma 7 con retícula de color vinoso. Procede de Mérida (Inédito).

17. Galbo con decoración geométrica de coloración marronácea delimitada con banda roja. Procede de las termas de Cáparra (Inédito).

18. Galbo con decoración geométrica de coloración marronácea. Procede de las termas de Cáparra (Inédito).

19. Galbo con decoración geométrica de coloración marronácea. Procede de las termas de Cáparra (Inédito).

20. Galbo y arranque de asa con decoración geométrica de líneas verticales de coloración vinosa. Procede de las termas de Cáparra (Inédito).

21. Galbo con decoración geométrica de líneas horizontales de coloración vinosa. Procede de las termas de Cáparra (Inédito).

22. Galbo con decoración geométrica de líneas horizontales de coloración vinosa y marronácea. Procede de las termas de Cáparra (Inédito).

23. Galbo con decoración geométrica de líneas horizontales de coloración vinosa. Procede de las termas de Cáparra (Inédito).
24. Galbo con decoración geométrica de líneas horizontales rojas y marrones. Procede de las termas de Cáparra (Inédito).

25. Galbo con decoración geométrica de líneas verticales de coloración vinosa. Procede de las termas de Cáparra (Inédito).

Catálogo de las piezas caracterizadas como de la Meseta Sur III (fig. 4)

1. Borde de cuenco con banda roja bajo el borde. Procede de Cáparra (Río-Miranda 2012: fig. 30).

2. Borde de cuenco con líneas negras verticales bajo el borde. Procede de Cáparra (Río-Miranda 2012: fig. 29).

3. Carena de cuenco con líneas marrones claras verticales delimitadas por bandas horizontales. Procede de Cáparra (Río-Miranda 2012: fig. 34).

4. Borde de cuenco con banda roja bajo el borde. Procede de Cáparra (Río-Miranda 2012: fig. 31).

5 . Borde de jarra monoansada con líneas rojas verticales. En el asa decoración oblicua roja. Procede de Cáparra (Río-Miranda 2012: fig. 48).

6. Borde de jarra biansada con banda roja negra en la zona de inflexión. Procede de Cáparra (Río-Miranda 2012: fig. 30).

7. Borde de Forma 7 con palmas rojas enmarcadas en arcos. Procede de Cáparra (Río-Miranda 2012: fig. 40).

8. Galbo con banda doble marrón oscura. Procede de Cáparra (Río-Miranda 2012: fig. 6).

9. Galbo con bandas múltiples marrón oscura. Procede de Cáparra (Río-Miranda 2012: fig. 9).

10. Borde de cuenco con líneas punteadas verticales. Procede de Cáparra (Río-Miranda 2012: fig. 24).

\subsection{El grupo Meseta Norte}

Este grupo es el menos numeroso de los documentados en nuestro estudio. A excepción de un fragmento, procedente de Mérida (Picado 2006: fig. 16), todos los demás son de la ciudad hispanorromana de Cáparra. Estos ejemplares ya han sido publicados de manera escueta en un reciente libro sobre las cerámicas romanas de este lugar (Río-Miranda 2012). A pesar de que son ejemplares descontextualizados, merece la pena que sean referidos al ser de las únicas alusiones a este tipo de material en suelo extremeño. 


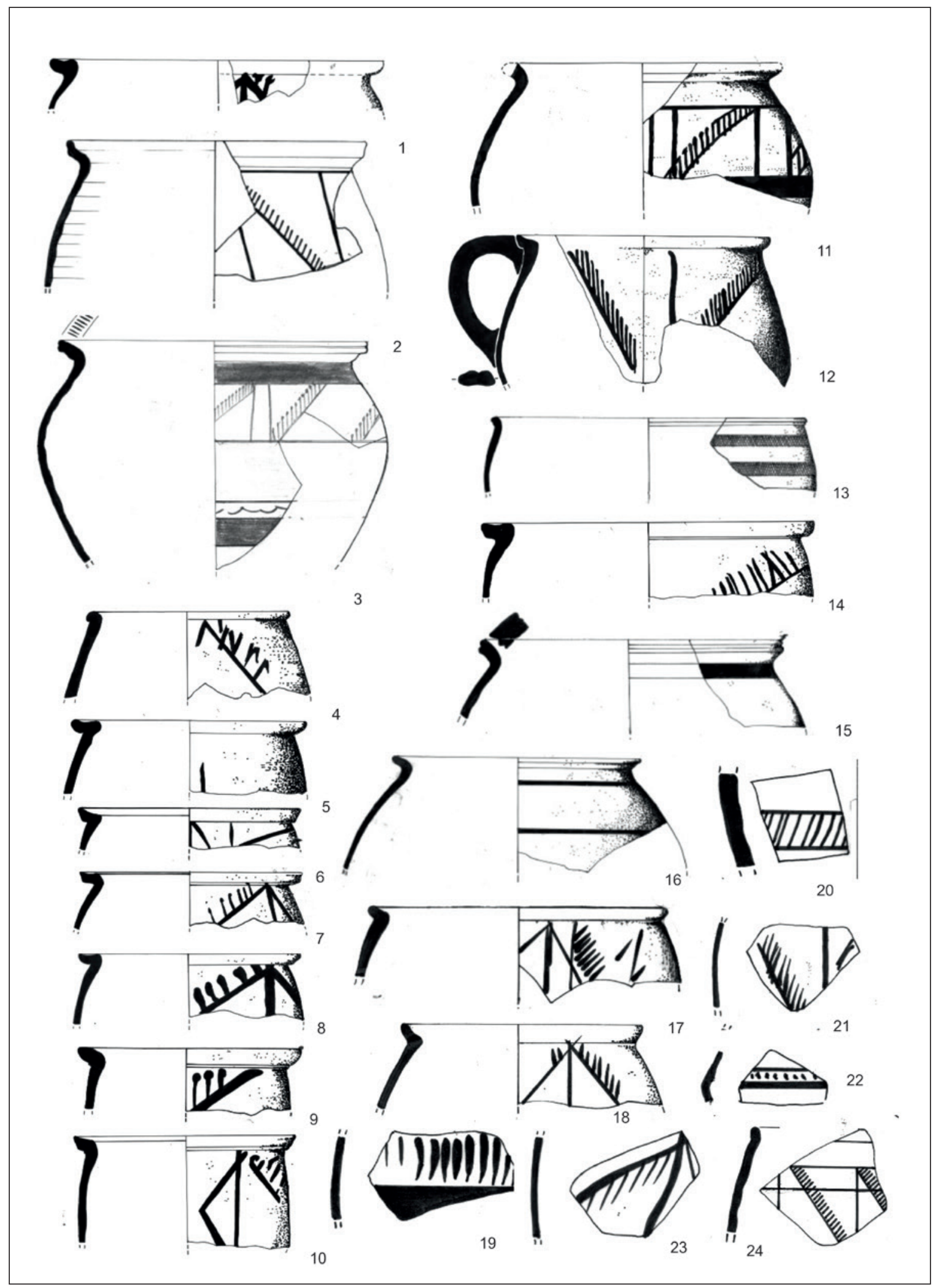

Figura 2. Piezas de estilo Meseta Sur localizadas en Cáparra I (a partir de Río-Miranda 2012). 


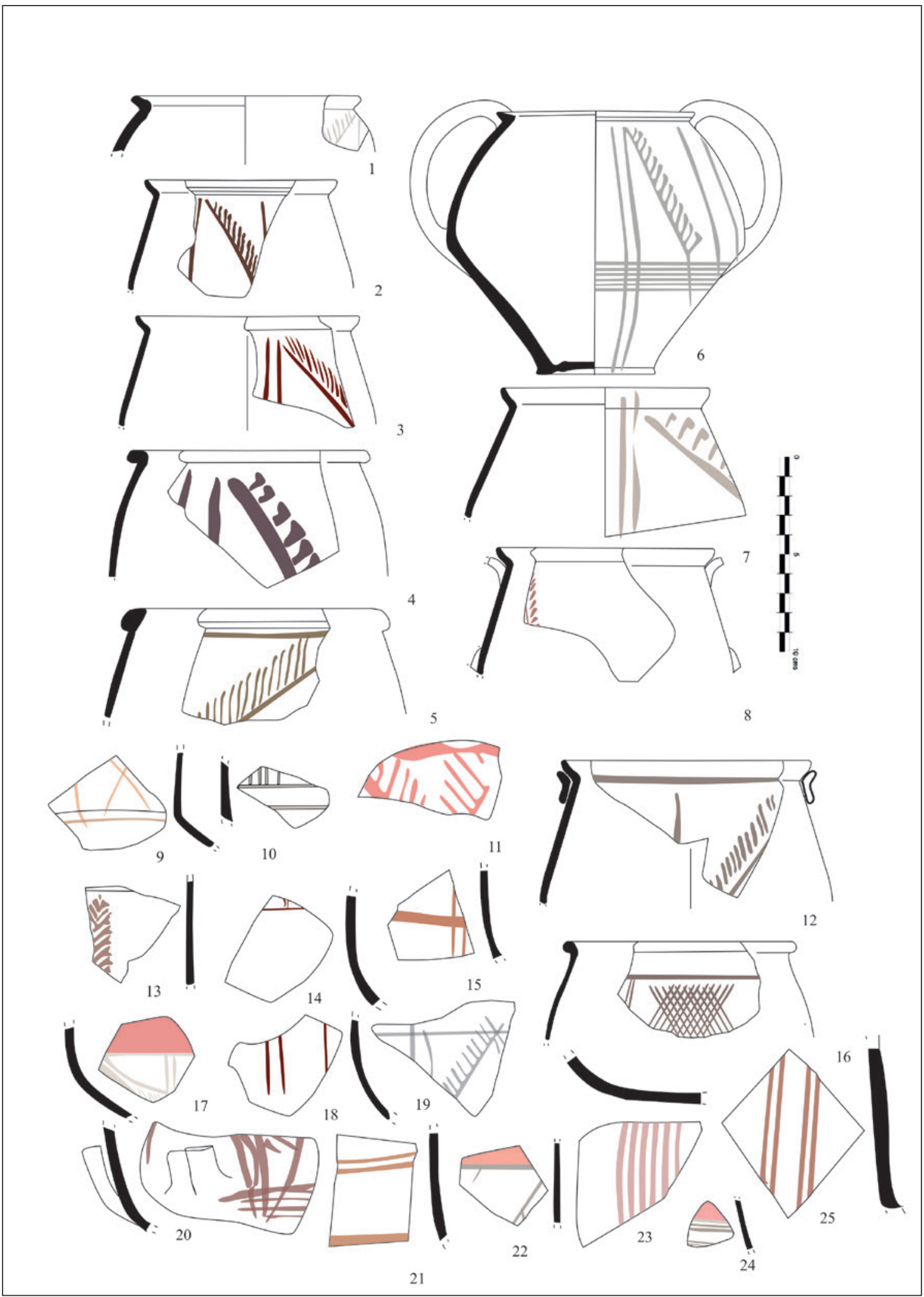

Figura 3. Piezas de estilo Meseta Sur localizadas en Cáparra II (a partir de Río-Miranda 2012, Abascal 1986 e inéditas). 


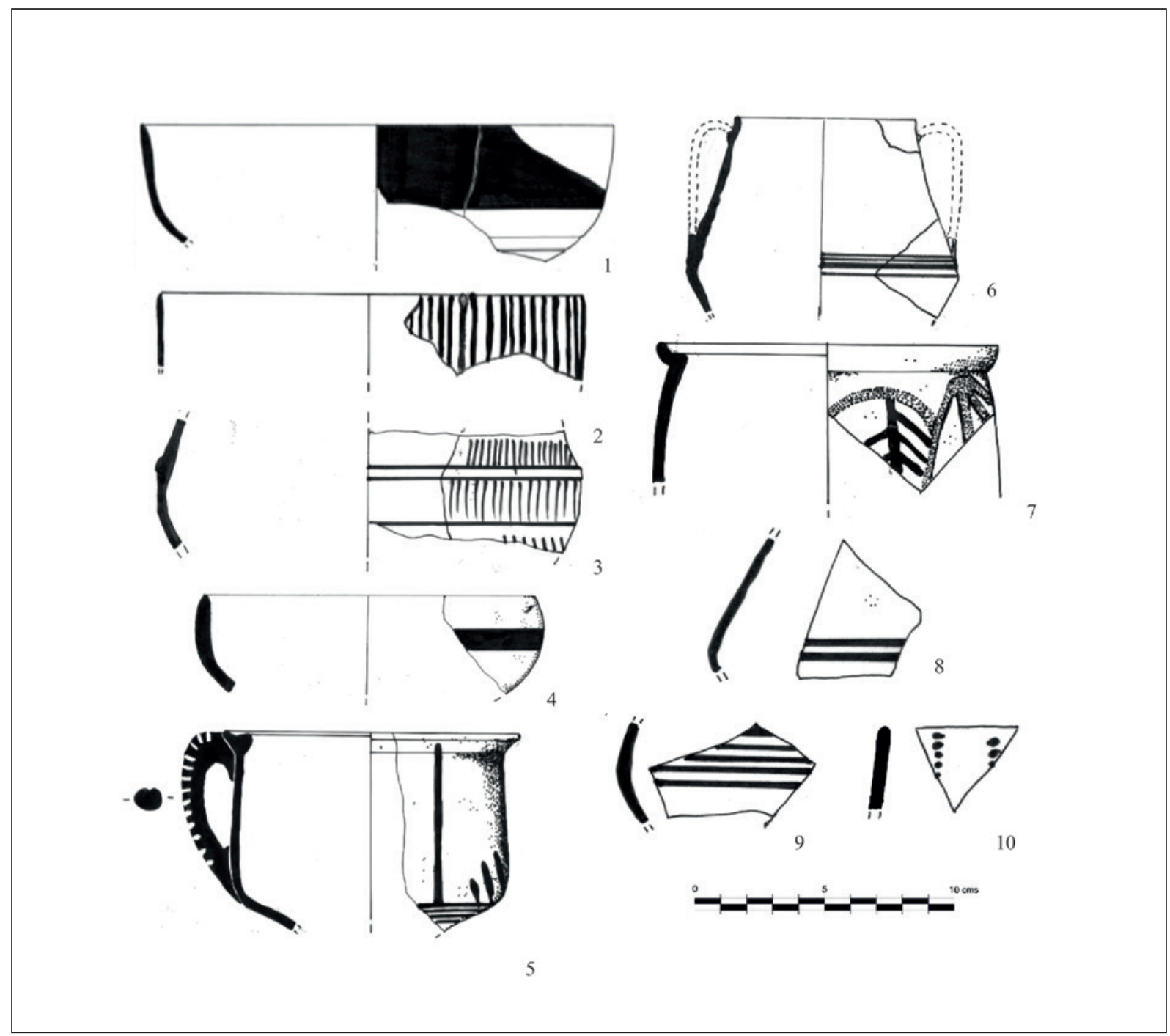

Figura 4. Piezas de estilo Meseta Sur localizadas en Cáparra III (a partir de Río-Miranda 2012).

Las piezas localizadas, tipológicamente, se insertan dentro de las formas comunes del repertorio de los talleres de la Meseta Norte -Clunia- y el Valle del Ebro (Abascal 1987: 63-73). Analizando por formas localizamos las siguientes piezas:

- Forma 1, se incluirían grandes vasos con amplios diámetros, tendencia globular en su zona superior y presentan una carena en su zona inferior, para cerrarse en un fondo anular y moldurado en la zona inferior. El borde localizado, al igual que la gran mayoría, se presenta redondeado. De este ejemplar hemos localizado tres ejemplares. El primero de ellos (fig. 5, $n^{\circ} 1$ ), aunque fragmentado, nos permite comprender el desarrollo genérico de la pieza. En la parte superior aparece decoración pintada de negro metopada con escenas de pájaros y la zona inferior con arcos invertidos (Abascal 1987: 63-64). A este ejemplar debemos unir dos fragmentos con decoración metopada que enmarcan aspas con abultamientos (fig. 5, n ${ }^{\circ}$ 5-6).

- Forma 3, esta es la forma más documentada en los talleres productores. Corresponde a un cuenco carenado y decorado, en exclusividad en la parte superior de la pieza. Los tres ejemplares localizados (fig. 5, $\mathrm{n}^{\mathrm{o}} 2,7 \mathrm{y}$ con dudas 4 ) presentan la misma decoración, es decir, metopada y enmarcando aspas con brazos engrosados. Tipológicamente, los $n^{\circ} 2$ y 7 se podrían enmarcar en el subtipo 3a definido 
por Abascal (1986: 65), por el contrario el n $\mathrm{n}^{\mathrm{o}} 3 \mathrm{se}$ insertaría en el 3b (1987: 3). A este grupo hay que unirle un ejemplar que no se ajustaría canónicamente a este tipo, $\mathrm{n}^{\circ} 4$. Sería un cuenco carenado pero exvasado en su parte superior, a diferencia de los tipos comúnmente localizados. A nuestro juicio, el problema radica en una mala plasmación gráfica de esta pieza, hecho que genera un posible error de asignación tipológica.

- Variante de la Forma 9, borde de tendencia vertical y truncado en la zona central para recoger posiblemente una tapadera (fig. $5, \mathrm{n}^{\circ} 8$ ).

De todas las piezas documentadas el motivo más reiterado es el de las aspas con bordes engrosados que, en nuestro caso, aparece adornando tanto a la forma 1 como a la 3. Su composición habitual es inserta en metopas verticales simples, hecho que se reitera en toda la producción (Abascal 1987: 78). El siguiente grupo decorativo es el fitomorfo y zoomorfo. Al respecto es interesante la aparición de aves paradas insertas en metopas reticuladas y acompañadas por tallos vegetales esquematizados, esquema muy similar al determinado como 8.1 en Bilbilis (Luezas y Martín-Bueno 1995: 243, nº 81).

Como ya hemos advertido, todas las piezas se encuentran descontextualizadas a excepción del ejemplar de Mérida (Picado 2006: fig. 16), el cual aparece acompañado por un acus crinalis y por una forma Mayet XLIIIa en paredes finas emeritenses que podemos ubicar en la segunda mitad del I d.C. (fig. 5, no 2). Esta cronología iría en consonancia con la establecida tradicionalmente de época flavia (Abascal 1986: 78), arco confirmado por el hallazgo en una de las casas de Uxama (Sánchez Simón 1995: fig. 1, nº 6). A pesar de ello, recientes hallazgos con contextos estratigráficos bien definidos como en la Casa de los Plintos de Uxama nos permiten hablar de una amplia perduración hasta el siglo III d.C. (García Merino et al. 1999: 232).

La aparición de estas piezas supone añadir un nuevo arco de consumo a las mismas, las cuales, hasta el momento, habían quedado relegadas a la zona norte de la Península (Abascal 1986: 80-82). A pesar de ello, el débil número documentado no es más que el reflejo de un fenómeno muy puntual y basado en contactos esporádicos que habrá que analizar usando otras variables, caso de la venida de otras cerámicas de procedencia meseteñas o el flujo de población oriunda de la Meseta portadora de enseres propios.

$$
* \quad * \quad *
$$

Catálogo de las piezas caracterizadas como de la Meseta Norte (fig. 5)

1. Borde y panza forma 1 en cerámica pintada procedente de la Meseta Norte. Decoración metopada en la zona superior con figuras zoomorfas. Zona inferior con cenefa de arcos invertidos. Procedencia: Cáparra (Río-Miranda 2012: fig. 26).

2. Perfil complejo forma 3 a en cerámica pintada procedente de la Meseta Norte. Decoración metopada enmarcando aspas con extremos engrosados. Procedencia: Mérida Bibliografía (Picado 2006: fig. $\left.16, n^{\circ} 1\right)$.

3. Borde de forma $3 b$ en cerámica pintada procedente de la Meseta Norte. Decoración metopada enmarcando elementos fitomorfos entre dos registros horizontales. Procedencia: Cáparra (Río-Miranda 2012: fig. 28).

4. Borde de variante de la forma 3 en cerámica pintada procedente de la Meseta Norte. Decoración metopada enmarcando aspas con extremos engrosados. Procedencia: Cáparra (Río-Miranda 2012: fig. 27).

5. Galbo de la forma 1 en cerámica pintada procedente de la Meseta Norte. Decoración metopada enmarcando aspas con extremos engrosados. Procedencia: Cáparra (Río-Miranda 2012: fig. 37).

6. Galbo de la forma 1 en cerámica pintada procedente de la Meseta Norte. Decoración metopada enmarcando aspas con extremos engrosados. Procedencia: Cáparra (Río-Miranda 2012: fig. 38).

7. Borde de la forma 3 a en cerámica pintada procedente de la Meseta Norte. Decoración metopada enmarcando aspas con extremos engrosados. Procedencia: Cáparra (Río-Miranda 2012: fig. 27/1).

8. Borde de la forma 9 en cerámica pintada procedente de la Meseta Norte. Decoración metopada con aspas dobles. Procedencia: Cáparra (Río-Miranda 2012: fig. 25).

\subsection{El grupo caparense}

Junto al consumo de piezas pintadas de la Meseta Sur, en el municipio de Cáparra así como en el Valle de Alconétar, se percibe un grupo homogéneo en rasgos compositivos y formales y cuya concentración se focaliza en exclusividad en esta zona norte. Sus pastas genéricamente serían las definidas como del tipo E.

Este hecho nos ha permitido la licencia de hablar de un posible grupo productivo local-regional que, en parte, ya fue anunciado por Abascal. Las pastas podrían 


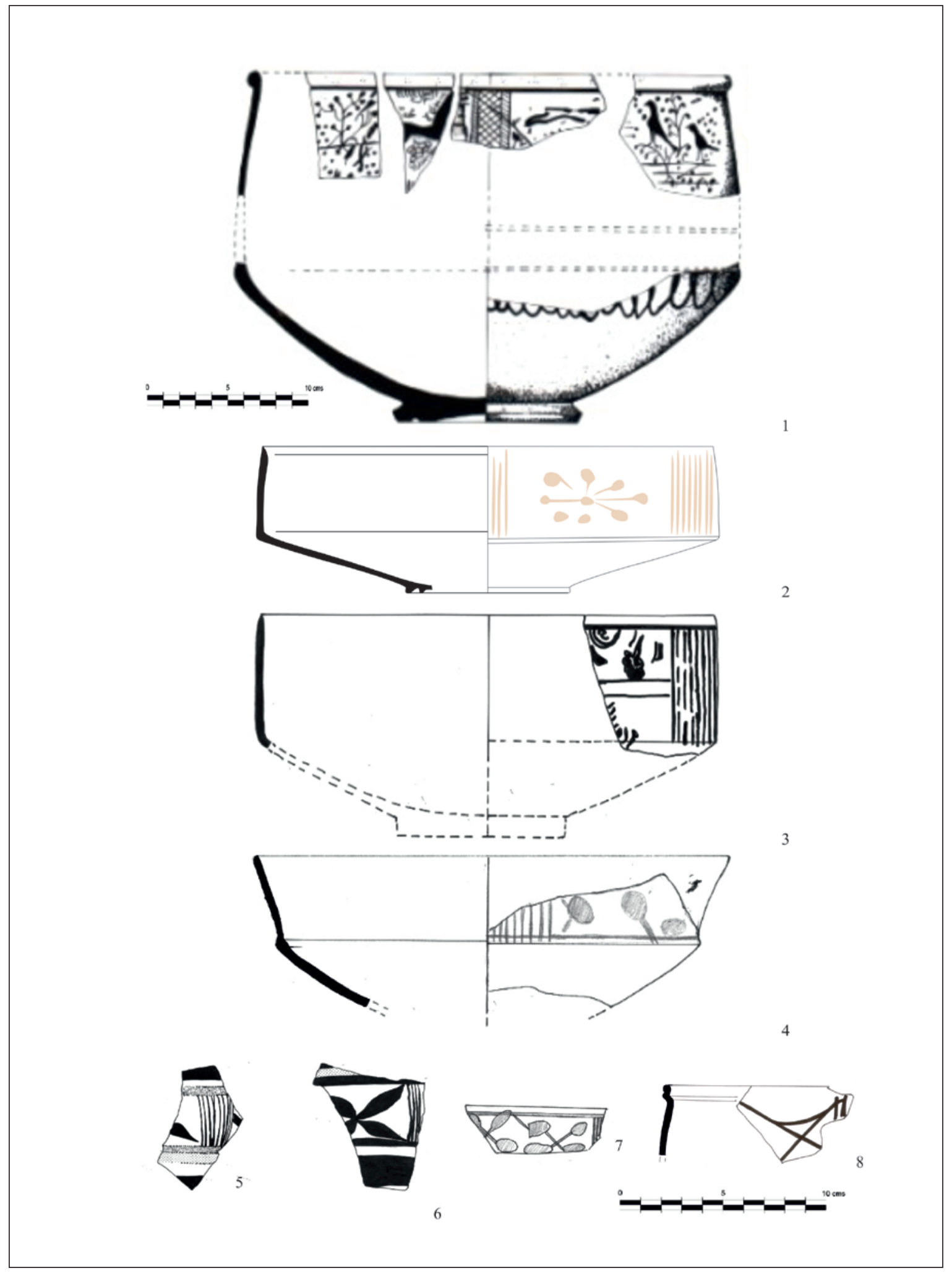

Figura 5. Fragmentos cerámicos del tipo Meseta Norte localizados en Extremadura (a partir de Picado 2006 y Río-Miranda 2012). 
asimilarse al grupo de las de la Meseta Sur, pero presentan fuertes divergencias como es su amasado extremo o el tratamiento espatulado al exterior. También la homogeneidad formal es otro de los elementos comunes. Al respecto, seis son las formas que aparecen y todas ellas presentan un esquema compositivo similar con líneas perpendiculares al eje de la pieza.

En primer lugar, aparece un tipo de urna globular con cuello truncado y borde y acabado exvasado. El labio presenta dos variantes, una primera moldurado triple y otra con borde redondeado simple. Podría asimilarse a la forma 35 de Abascal pero con fuertes variantes que alejan del prototipo (fig. $6, n^{\circ} 1-3$ ). En todas ellas se repite el esquema decorativo de líneas horizontales paralelas al borde así como una cenefa de ondas en todo su cuello. Por consiguiente, en lo que respecta a las urnas se observa una reiteración del uso de la composición lineal en las zonas más angulosas.

La siguiente forma correspondería a una variante de la Abascal 18, a modo de olla biansada con borde rectangular y con tendencia vertical u horizontal (fig. 6, $\mathrm{n}^{\mathrm{o}} 4$ ). Esta forma, también con una reinterpretación más libre, puede verse en la producción emeritense. Como veremos a posteriori la producción de la capital se basa formalmente en unos recipientes biansados comunes de fines del I d.C. Sin embargo las producciones caparenses se asemejan más al tipo Abascal 18 que, con aires meseteños, imitarían a juicio de Abascal a la F. 18 (Abascal 1986: 109).

Para finalizar, encontramos un cuenco, el único en todo este repertorio, con borde exvasado al exterior y con fuertes similitudes con la producción de sigillata, más concretamente con la forma Hisp. 4 y que únicamente podríamos asociar a la Abascal 16. Esta presenta varias líneas de coloración ocre en la panza de la misma, hecho que se acompaña con incisiones (fig. 6, $\mathrm{n}^{\circ} 7$ ).

Todas estas piezas proceden de contextos altoimperiales, lo mismo que ocurría con las del grupo de la Meseta Sur.

\section{Catálogo de las piezas caparenses (fig. 6)}

1. Borde de urna en cerámica pintada caparense variante Abascal 35. Decoración lineal y ondulada en la zona superior de coloración vinosa. Procedencia: Termas de Cáparra (Inédito).

2. Borde de urna en cerámica pintada caparense variante Abascal 35. Decoración lineal en la zona superior de coloración vinosa. Procedencia: Termas de Cáparra (Inédito).

3. Borde de urna en cerámica pintada caparense variante Abascal 35. Decoración lineal y ondulada en la zona superior de coloración vinosa. Procedencia: Termas de Cáparra (Inédito).

4. Borde de olla biansada en cerámica pintada caparense variante Abascal 35. Decoración lineal en la zona superior y central de la panza de coloración vinosa. Procedencia: Termas de Cáparra (Inédito).

5. Borde de olla en cerámica pintada caparense. Decoración lineal en la zona superior y central d la panza de coloración vinosa. Procedencia: Termas de Cáparra (Inédito).

6. Borde de olla biansada en cerámica pintada caparense. Decoración lineal en la zona superior de coloración vinosa. Procedencia: Termas de Cáparra (Inédito).

7. Borde de cuenco en cerámica pintada caparense Abascal 16. Decoración lineal y ondulada en la zona superior de coloración vinosa. Procedencia: Termas de Cáparra (Inédito).

\subsection{El grupo emeritense}

Previamente hemos lanzado algunas ideas sobre la posible existencia de un taller afincado en la capital de la Lusitania. Es bien conocida la aparición de este tipo de piezas en tierras extremeñas desde época protohistórica (algunos ejemplos los encontramos en Rodríguez Díaz 1995: lám. 5 y 6). En época romana, las primeras evidencias de este tipo de acabados los encontramos en cronología augustea, de hecho en los escasos ejemplos de contextos augusteos en Mérida es común su aparición, caso de la Escuela de Hostelería (Bustamante y Heras 2013), el templo de la c/Viñeros (Aquilué y Bello 2009: lám. 21, no 6 y lám. 23, nº 9-10) o el solar de la c/Almendralejo 41 (Bustamante 2013) -fig. 7-. Al respecto, aunque de clara tradición regional, con la aplicación de bandas pintadas vinosas y blancas sobre formas de morfología muy similar a las protohistóricas, no creemos que hayan sido producidas en suelo emeritense. Sus pastas rojizas, quebradas y con inclusiones calcáreas nos hacen ubicar su foco productivo en una zona alejada del solar emeritense. Esta similar dinámica de aparición en época augustea se da en otras ciudades como Carthago Nova, bien recogido de antiguo (Ruiz 1988: 621).

Las pastas con las cuales están hechas las piezas que reciben estos recubrimientos son de los tipos B, C 


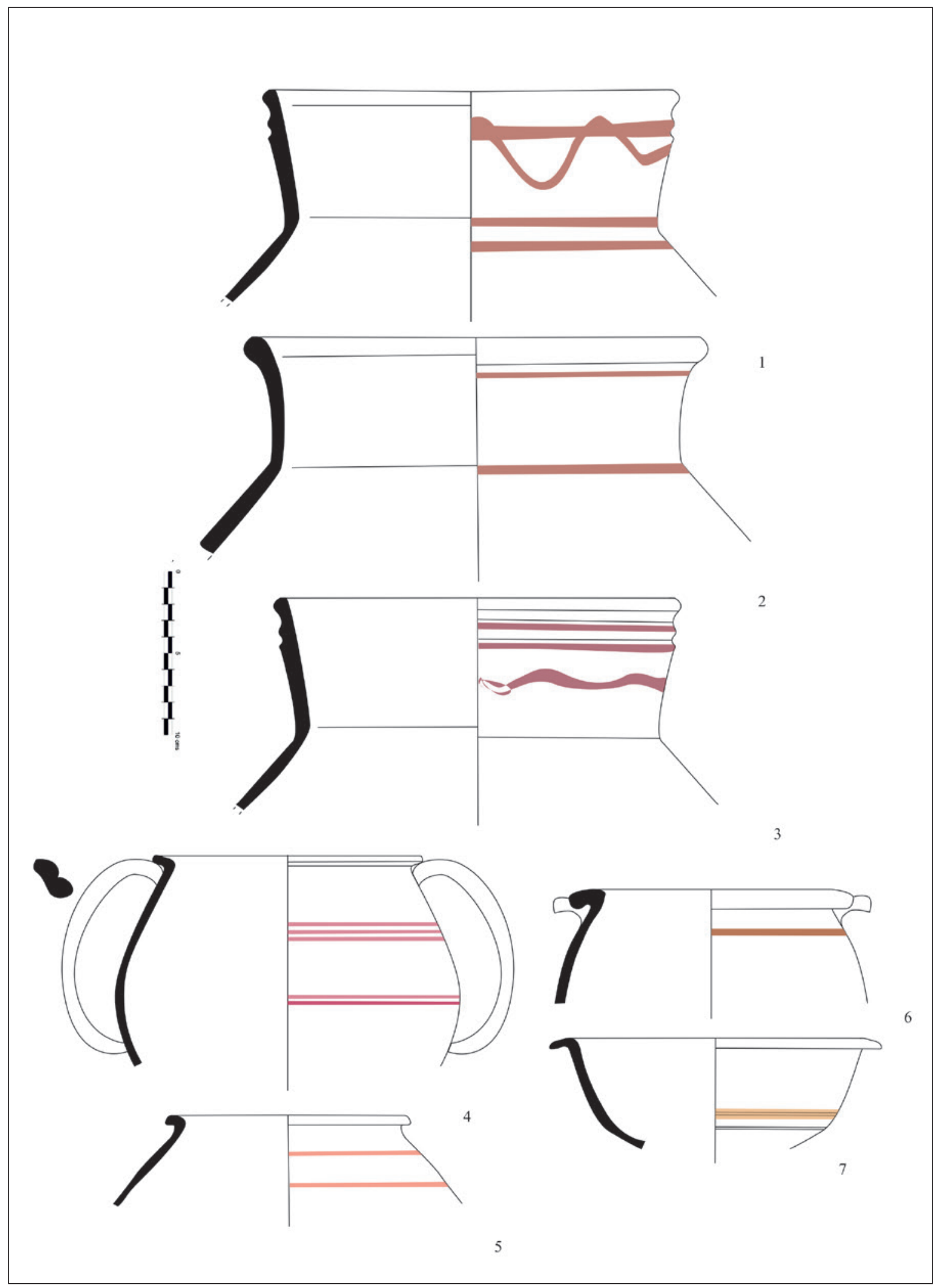

Figura 6. Ejemplos de cerámica caparense. 
y D. El tipo más común corresponde a la $\mathrm{C}$, el cual es el usual en el servicio común local. Por el contrario el B es el que continuamente se ha designado como de imitación de paredes finas. Presenta consistencia blanquecina y fuertes inclusiones. Indicamos que de los tres tipos el más extraño es el D, que únicamente aparece sobre dos vasos, los cuales, con total seguridad, forman parte de un mismo servicio. Esta variedad en las pastas también apoya nuestra teoría de que no estamos ante una producción estandarizada, sino más bien ante decoraciones aleatorias que en un momento determinado se aplican. Esto no excluye que se intuya un patrón similar a la hora de elegir los vasos y las zonas a decorar. Al respecto, se tiene predilección por las piezas destinadas al servicio e ingestión de líquidos. Dentro de esta amalgama, se observa una cierta tendencia a usar vasos innovadores y poco comunes en el repertorio, caso de las botellas bitroncocónicas, cálices hemiesféricos o cilíndricos. Otro de los elementos significativos es la predilección por los colores tierras y rojizos, quedando excluidos los tonos negros que sí predominan en las producción de la Meseta Sur.

Para la producción emeritense hemos logrado individualizar tres grupos compositivos que, en ningún momento, adquieren la identidad y homogeneidad compositiva que se observa para el grupo de la Meseta Sur y Norte. Por consiguiente, estos grupos responden más a motivos que se reiteran caprichosamente en el seno de un taller.

- Uso del zig-zag en posición horizontal (como p.ej. la fig. $6, \mathrm{n}^{\circ} 1$ ). La técnica usada es la del pincel de grosor medio y trazo limpio. Los acabados de los zig-zag son angulosos y, en algunas ocasiones, se advierten trazos discontinuos, hecho generado al levantar el pincel de la superficie. Este elemento común se puede aderezar bien con pequeños motivos entre las estribaciones, que pueden ser líneas simples o curvadas que, en algunos casos, se confunden con los trazos básicos. En otra ocasión esta cenefa se delimita su zona inferior por una línea de ondas. Esta composición aparece reiteradamente sobre formas globulares que realzan el carácter anguloso de esta decoración. En los ejemplos localizados se observa una concentración de dicho motivo en la mitad superior del vaso, quedando el registro inferior libre. Predomina el uso de tonos terrosos. Cronológicamente aparecen tanto en vasos datables a fines del I d.C., caso de las pequeñas ollas biansadas, como en ejemplares más moderno, como una olla localizada en un contexto de fines el III d.C.
- Composición lineal. Es el grupo más común, quizás por la simplicidad del motivo y su fácil ejecución (ejemplo de ello fig. 6, no 2). Esta decoración está activa en suelo extremeño desde época protohistórica. El momento de mayor efervescencia lo encontramos en cronología augustea, siendo un clásico en el servicio del momento. Dentro de este grupo puede haber dos variantes: la simple y la combinada. La simple es aquella en la que únicamente aparecen líneas perpendiculares al eje de la pieza y equidistantes entre ellas. Suelen aparecen por parejas o bien por conjuntos, quedando entre dichos grupos un espacio en reserva. En ningún momento se percibe un rayado total de las piezas. En lo que se refiere a las botellas, casi siempre aparecen ubicadas estas líneas de los hombros hacia abajo, quedando el cuello y la boca desprovistos de decoración. Los tonos usados van desde claros terrosos hasta vinosos. Las líneas suelen presentarse con un grosor medio, hecho que se reitera en los otros ejemplares. Esto nos permite hablar de pinceles muy estandarizados. La variante combinada es aquella en la que, además de líneas perpendiculares al eje de la pieza, se añaden puntos que suelen aparecer sobre las líneas o bien entre ellas. Esta línea de puntos solo se usa en botellas y ollas, las cuales presentan perfiles angulosos, así como en un cáliz cilíndrico que forma juego por pasta y decoración con una de las botellas. Cronológicamente ya hemos indicado la amplia diacronía existente en el uso de la línea simple. Solo podemos realizar alguna apreciación en relación al uso de los puntos, muy centrado en la segunda mitad del I d.C. (como la pieza fig. 8, nº 4 o 7).

— Utilización de las ondas. Se trata del fenómeno más tardío en lo que a decoración pictórica se refiere en los talleres emeritenses, perpetuándose en época visigoda y posterior. Estas ondas pueden aparecer horizontales o verticales. En algunos casos se pueden incluso combinar con incisiones, que claramente nos inducen a pensar en prácticas muy cercanas al mundo godo (caso de la pieza fig. $8, \mathrm{n}^{\mathrm{o}} 5$ ).

Es importante indicar la ausencia total de motivos vegetales y fitomorfos en todo el repertorio emeritense, hecho que se aleja de los esquemas anteriormente tratados. Asimismo dentro de los esquemas geométricos también se echa en falta la aparición de círculos y semicírculos concéntricos, hecho quizás reforzado por ser un motivo muy recurrente en la tradición indígena más levantina y celtibérica (Luezas y Martín Bueno 1995: 239).

- Fuera de estos grupos compositivos tenemos que hablar de dos ejemplos muy concretos de aplicación 


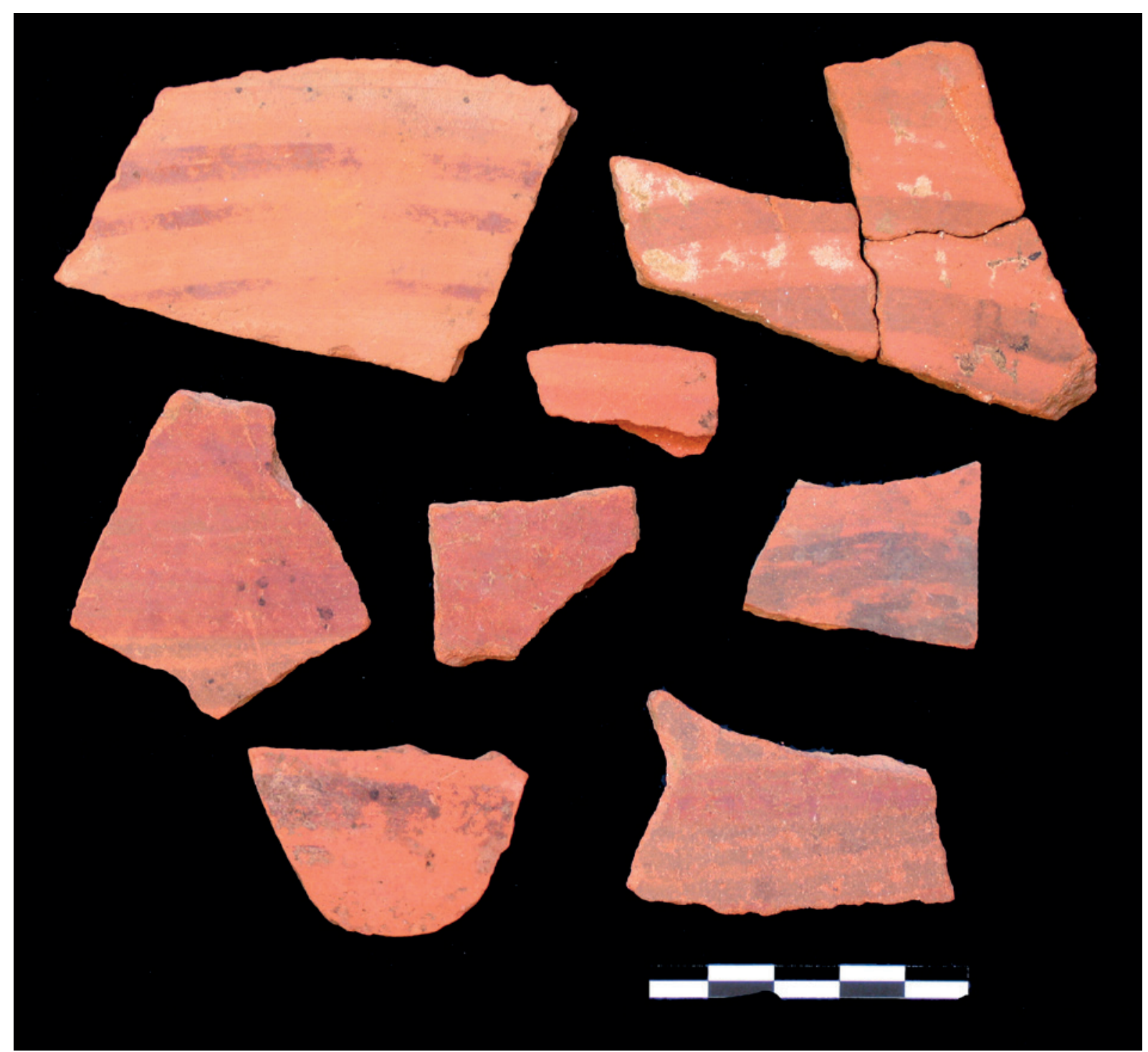

Figura 7. Fragmentos a bandas pintadas de cronología augustea procedentes de la c/Almendralejo 41, Mérida.

pictórica que van más allá de la simple decoración. Nos referimos a los tituli picti sobre algunos vasos. Al respecto tenemos el cáliz de $\mathrm{A} \cdot \mathrm{NI} \cdot \phi \mathrm{YC}$ (fig. 8, $\mathrm{n}^{\mathrm{o}} 7$ ), un ejemplar depositado de antiguo en el MNAR (Álvarez Sáez de Buruaga 1956: 2-3) y datado como un ejemplar de época tardía (Abascal 1986: $\mathrm{n}^{\circ}$ 813) que, como veremos a posteriori, creemos que habría que adelantarlo, como mínimo, a inicios del II d.C. La inserción de epigrafía en este ejemplar es aleatoria, aprovechando un hueco dejado entre cenefas lineales. El vaso presenta claramente una composición lineal realizada inicialmente, como puede deducirse del hecho de que las letras estén escritas parcialmente encima de ella. El otro ejemplar que hemos localizado con epigrafía pintada corresponde a una jarra de la villa de Torre Águila (Montijo, Badajoz) ${ }^{3}$. La pieza está exenta de decoración y únicamente en su cuello se inserta la inscripción FELIX. Ambas piezas aluden directamente al nombre, creemos, que del propietario, entendiendo que el productor no debe de tener un papel tan predominante como para que aparezca su nombre en un espacio de tanta importancia. Es interesante el uso del color rojo en ambas

3. Agradecemos los datos aportados por el Dr. G. Rodríguez. 
inscripciones, claramente para ayudar a resaltar el mensaje sobre su fondo (fig. $8, \mathrm{n}^{\mathrm{o}} 7$ ).

Ya hemos ido esbozando la cronología de las composiciones y, por ende, de las formas. Al respecto, se observa un predominio de las altoimperiales y una reiteración del uso de la pintura para tipos vinculados con el consumo e ingestión de líquidos.

— Las botellas (fig. 8, no 1 y 3-6 y fig. 9, no 2-3): predominan las piezas globulares y monoansadas. Aparecen reiteradamente en contextos funerarios, en compañía de recipientes típicos de época romana, caso de las paredes finas. Los ejemplares más antiguos se retrotraen a época flavia, más concretamente un ejemplar con carena en la zona central y boca triangular. De manera simultánea aparecen las globulares muy estilizadas con bordes muy moldurados. A partir de mitad del II d.C. no encontramos evidencias del consumo de estas formas. Ya en momentos avanzados aparecen ejemplares muy toscos biansados que nos anuncian un modo productivo sensiblemente distinto a los momentos previos.

- Las jarritas individuales biansadas (fig. 9, no 5-10): presentan fuertes reminiscencias de las paredes finas. Los ejemplares más antiguos presentan una diferenciación del cuerpo muy abrupta, con la aparición de fuertes baquetones desde los que arrancan las asas y que permiten delimitar las dos zonas a decorar. A medida que avanza el tiempo, esas fuertes incisiones van perdiendo entidad, convirtiéndose los vasos en recipientes más globulares. Al menos, por contextos estudiados, tenemos hasta el siglo III d.C. algunos de estos ejemplares.

- Las ollas: son las que irrumpen desde el inicio, de hecho los contextos augusteos presentan estas formas (fig. 8, $\mathrm{n}^{\mathrm{o}} 2$ ). Dentro de esta amalgama es muy interesante una olla globular monoansada ubicada en un depósito funerario del III d.C. con decoración de (o "en”) zig-zag (fig. 9, no 4).

- Los cálices: podemos decir que esta es una de las novedades del repertorio que estamos valorando (fig. 8, $\mathrm{n}^{\mathrm{o}} 7$ y 8). La primera de ellas sería una copa globular con cenefa de ondas y pintura blanca, apriorísticamente podría parecer que estamos ante un ejemplar tardío, pero su inserción en una tumba con una pieza del tipo Mayet XLIII evolucionada nos plantea que estamos en la mitad del II d.C. El segundo de los ejemplares sería un vaso cilíndrico que, por composición y por pasta de una jarra localizada con decoración muy similar, lo ubicamos a inicios del II d.C. y no en momentos más tardíos como se había propuesto inicialmente.

- El vaso cilíndrico con inscripción griega formaría servicio con una de las jarras localizadas. Abascal había apostado por una cronología tardía para dicho ejemplar. El hecho de que en pasta y decoración sea igual a un ejemplar localizado en el vertedero de la c/Almendralejo, fechado a inicios del II d.C., se debe unir al contexto de aparición publicado de antiguo (Álvarez Sáez de Buruaga 1956: 2-3), en el que aparece una copa completa de sigillata marmorata de la forma Drag. 29 y una píxide en paredes finas emeritenses (Bustamante 2013: Lám. 23, nº 1).

A diferencia de las producciones meseteñas, las cuales presentan objetivos claramente comerciales, como una producción masiva para la exportación -de ahí la reiteración y estandarización de formas y motivos decorativos (Abascal 1986: 26)-, las producciones lusitanas se mueven en cortos radios geográficos que ponen de manifiesto que el deseo comercial implícito en las otras producciones no está presente.

Cuando valoramos todas las piezas del grupo emeritense, obtenemos como primera gran conclusión que hay una mayor preferencia por decorar piezas de reducidas dimensiones, caso de las ollas biansadas. A este hecho le debemos unir otras características que resumen la producción pintada iniciada en época julio-claudia, caso de la monotonía de las formas, la simplificación de los motivos decorativos o la decoración ordenada por frisos (Abascal 2008: 430). Esto nos permite afirmar que, aunque estamos ante un foco productor autónomo, sí parece sumergirse de lleno en la producción pintada.

No se aprecia influencia de agentes externos, como se observa en las cerámicas meseteñas, las cuales parecen bascular por las fluctuaciones de las sigillatas altoimperiales (Abascal 2008: 431). Son formas típicas del repertorio común (para más datos sobre el mismo Sánchez Sánchez 1992 y Bustamante 2012), aunque se podría vislumbrar cierto aire de imitación en las ollas biansadas de las formas de paredes finas locales Mayet XLIII (1975). Destacamos, como pasa en otros conjuntos, la ausencia de formas abiertas, principalmente platos como ocurre en la Casa de los Plintos de Uxama (García Merino et al. 2009: 245).

La particularidad de este taller radica en la ausencia de cualquier influencia previa, frente al modus operandi de otras oficinas en las cuales el sustrato indígena es palpable en su producción.

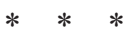


Catálogo de las piezas emeritenses recogidas I (fig. 8)

1. Botella monoansada con borde diferenciado. Decoración en la panza de coloración vinosa, cenefa ondulada ubicada entre líneas dobles. Mérida, sin procedencia, depositada en el Museo Nacional de Arte Romano (Abascal 1987: $n^{\circ} 819$ ).

2. Urna funeraria con decoración lineal pintada de coloración negruzca. Mérida, sin procedencia, depositada en el Museo Nacional de Arte Romano (Abascal 1987: $\mathrm{n}^{\circ}$ 604).

3. Botella monoansada con borde moldurado. Decoración a bandas pintadas muy deteriorada. Mérida. Procedente de las antiguas excavaciones del teatro o de la necrópolis oriental en las inmediaciones del teatro. Depositada en el Museo Nacional de Arte Romano (Abascal 1987: $n^{\circ} 821$ ).

4. Botella monoansada con perfil cuadrangular en su tercio inferior. En la unión entre el cuello y el cuerpo, decoración a bandas lisas que enmarcan una línea punteada. En el tercio inferior, decoración de líneas paralelas. Mérida, depositada en el Museo Nacional de Arte Romano y procedente de la necrópolis oriental (Abascal 1987: $\mathrm{n}^{\circ}$ 814).

5. Botella biansada, presenta acanaladuras incisas en el cuello y borde. Decoración pintada combinada de líneas perpendiculares al eje de la pieza y ondas paralelas a su desarrollo. Mérida, depositada en el Museo Nacional de Arte Romano y procedente de la necrópolis de la República Argentina en el interior del sarcófago, s. III d.C. (Abascal 1987: n 818).

6. Botella monoansada con borde moldurado. Decoración a bandas pintadas muy deteriorada Procedente de las antiguas excavaciones de Floriano en las inmediaciones del teatro. Depositada en el Museo Nacional de Arte Romano (Abascal 1987: nº 820).

7. Cáliz de la forma 41 según la tipología Abascal (1986). Pieza engobada con decoración vinosa de líneas simples horizontales con dos bandas punteadas enmarcadas en puntos. En la zona central, titulus pictus $\mathrm{A} \cdot \mathrm{NI} \cdot \phi \mathrm{OYC}$. Mérida, procedente del Solar de la Empresa Corchera Extremeña, depositado en el Museo Nacional de Arte Romano. Cronología propuesta por Abascal muy tardía por paralelos (Álvarez Sáenz 1952-1953: 3, Abascal 1987: n 813, Sabio y Bustamante 2014: 60).

8. Cáliz variante de la forma Abascal 41. Perfil globular. Presenta decoración pintada blanca con dos líneas blancas onduladas horizontales. Mérida, procedente de la necrópolis sur de la ciudad.
Cronología aportada por su contexto, inicios del II d.C. (Méndez 2006: fig. 21).

Catálogo de las piezas emeritenses recogidas II (fig. 9)

1. Fondo de jarra con decoración a líneas horizontales blanquecinas paralelas en dos grupos. Mérida, necrópolis de la C/Almendralejo 41. Cronología fines del II d.C. (Inédito) 4 .

2. Borde de botella con decoración a líneas horizontales vinosas que enmarcan una franja de puntos amarillentos sobre aguada ocre. En la panza, de nuevo, líneas paralelas vinosas unidas entre sí por líneas verticales amarillentas. Mérida, necrópolis de la $\mathrm{C} /$ Almendralejo 41. Cronología mitad del I d.C., pasta similar a la pieza fig. 8, $\mathrm{n}^{\circ} 7$ (Inédito).

3. Botella monoansada y borde apuntado. Decoración pintada amarillenta con líneas paralelas equidistantes. En la zona superior, línea punteada. Mérida, necrópolis de la C/Almendralejo 41. Cronología de época Flavia (Bustamante 2013: lám. 23, nº 1).

4. Jarra monoansada de perfil ovoide. Decoración pintada en zigzag con líneas y "s" aleatorias entre los picos. Mérida, necrópolis de la C/Almendralejo 41 . Cronología mitad del II d.C. (Inédita).

5. Jarra biansada de perfil bitroncocónico. Decoración pintada a bandas paralelas en la parte inferior del cuerpo. Cronología, fin del I - inicios del II d.C. Depositado en el Museo Nacional de Arte Romano (Inédita).

6. Jarra biansada de perfil bitroncocónico. Decoración pintada a bandas paralelas en la parte inferior del cuerpo. Cronología, fin del I - inicios del II d.C. Depositado en el Museo Nacional de Arte Romano (Inédita).

7. Jarra biansada de perfil bitroncocónico. Decoración pintada en zigzag en su mitad superior; bajo esto, línea ondulada que actúa como separación de ambos registros. Cronología, fin del I - inicios del II d.C. Depositado en el Museo Nacional de Arte Romano (Inédita).

8. Jarra biansada de perfil bitroncocónico. Decoración pintada en zigzag en su mitad superior. Cronología, fin del I - inicios del II d.C. Necrópolis de la C/Almendralejo 41 (Inédita).

4. Estas piezas se encuentran depositadas en los almacenes del Consorcio de Mérida. 


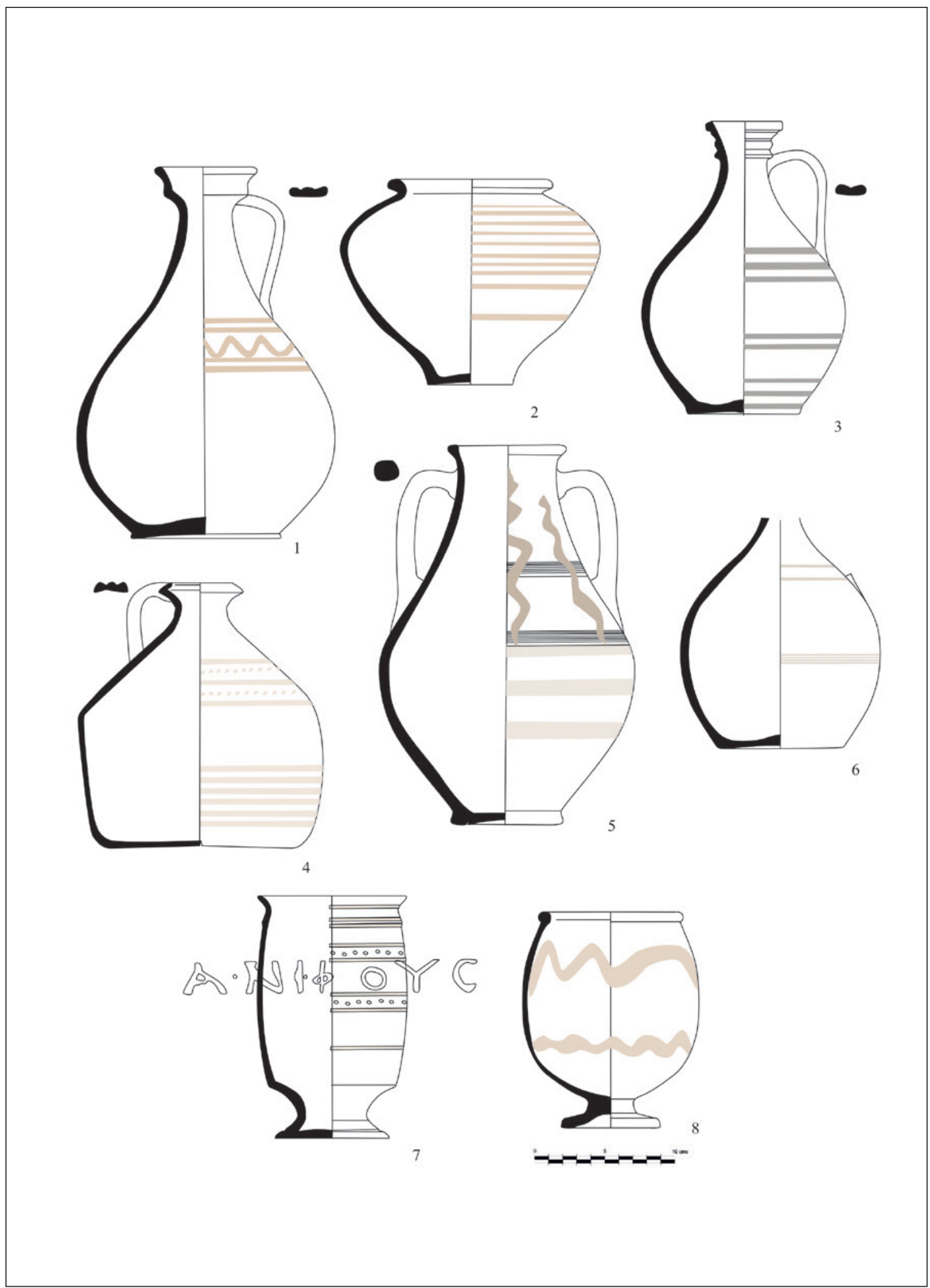

Figura 8. Piezas pintadas de producción emeritense (a partir de Abascal 1986 y piezas inéditas). 


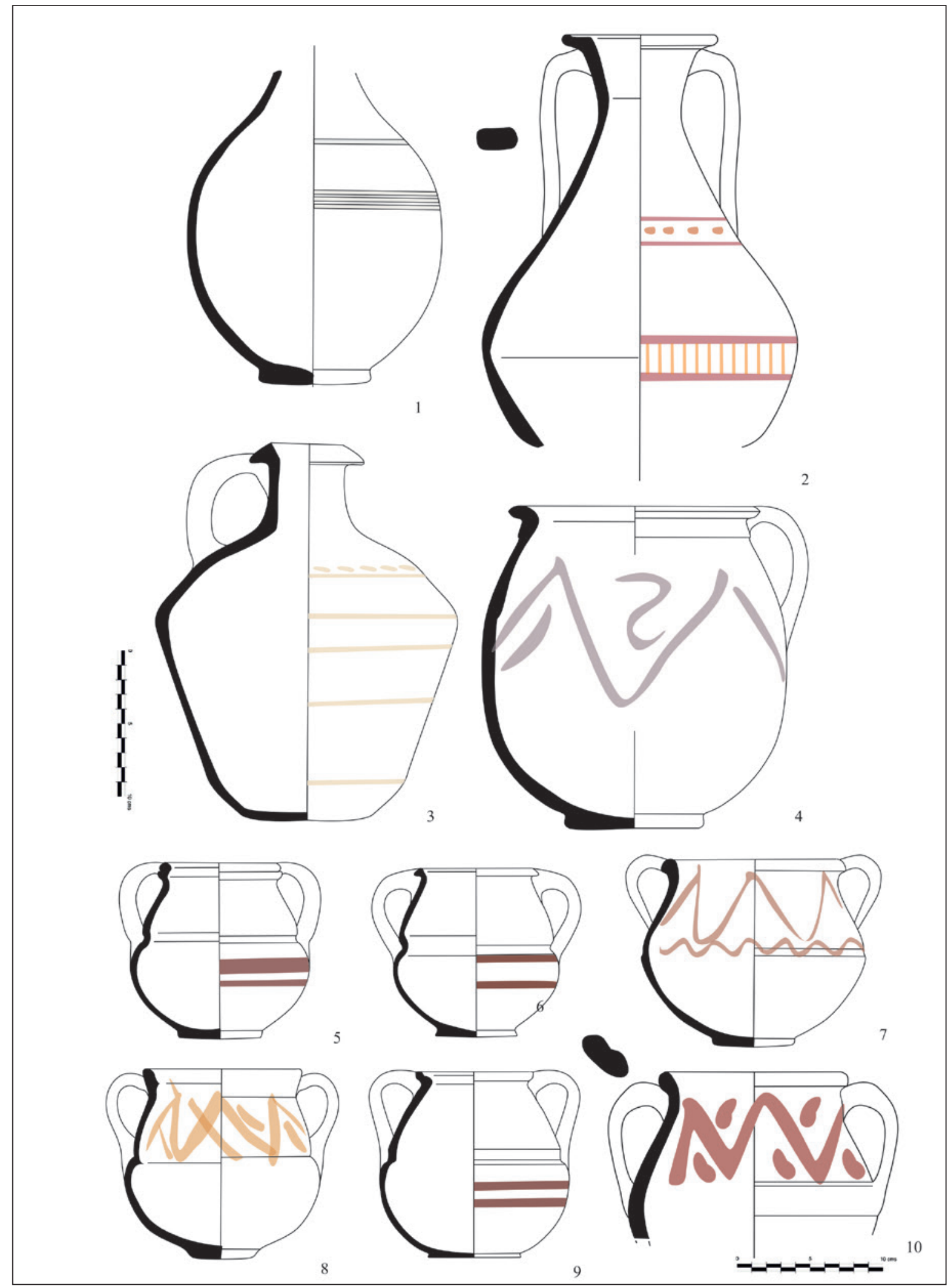

Figura 9. Piezas pintadas de producción emeritense. 
9. Jarra biansada de perfil bitroncocónico. Decoración pintada a bandas paralelas en la parte inferior del cuerpo. Cronología, fin del I - inicios del II d.C. Depositado en el Museo Nacional de Arte Romano (Inédita).

10. Jarra biansada de perfil bitroncocónico. Decoración pintada en zigzag en su mitad superior. Cronología, fin del I - inicios del II d.C. Necrópolis de la C/Almendralejo 41 (Inédita).

Catálogo de las piezas emeritenses recogidas III (fig. 10)

1. Borde de olla con decoración de líneas oblicuas verticales de coloración marronácea. En el frontal del borde superior, decoración de línea. Procedente de Garrovillas de Alconétar (Abascal 1986: n 467).

2. Olla de borde simple con decoración pintada vinosa de línea de puntos delimitada en la parte superior por una línea simple. Procede del solar del Museo Nacional de Arte Romano (Abascal 1986: $\left.\mathrm{n}^{\circ} 815\right)$.

3. Olla de borde simple con decoración pintada vinosa de línea de puntos, delimitada en la parte superior por una línea simple. Procede del solar del Museo Nacional de Arte Romano (Abascal 1986: nº 817).

4. Borde de olla con decoración lineal horizontal vinosa. Líneas oblicuas pintadas de tonalidad vinosa en el borde. Procedente de Cáparra (Abascal 1986: $n^{\circ} 532$ ).

5. Borde de olla con decoración lineal horizontal vinosa. Procedente de Alconétar (Abascal 1986: $\mathrm{n}^{\circ}$ 532).

6. Asa con decoración pintada punteada de coloración marronácea y decoración lineal en el cuerpo del recipiente. Procedente de Alconétar (Abascal 1986: $\left.n^{\circ} 426\right)$.

7. Galbo de olla pintada a líneas horizontales que enmarca una cenefa ondulada. Procedencia ignota, depositada en el Museo Nacional de Arte Romano (Abascal 1986: $\mathrm{n}^{\circ} 825$ ).

8. Galbo de olla pintada a líneas horizontales vinosas. Procedencia ignota, depositada en el Museo Nacional de Arte Romano (Abascal 1986: n 826).

9. Galbo de olla pintada a bandas vinosas. Procedencia ignota, depositada en el Museo Nacional de Arte Romano (Abascal 1986: $n^{\circ} 824$ ).

10. Olla con decoración pintada vinosa de línea de puntos, delimitada superiormente por una línea simple. Procede del solar del Museo Nacional de Arte Romano (Abascal 1986: n 817).
11. Galbo de olla pintada a líneas horizontales naranjas que enmarcan una cenefa ondulada. Procedencia ignota, depositada en el Museo Nacional de Arte Romano (Abascal 1986: $\mathrm{n}^{\circ}$ 825).

\section{LA APLICACIÓN DE PINTURA EN SIGILLATA HISPÁNICA}

Durante el desarrollo del estudio focalizado en la sigillata hispánica en Mérida, se localizó un ejemplar de pie de un cáliz del tipo Hisp. 94 con decoración geométrica datada en época flavia (Bustamante 2013: 148150, lám. 169). El interés de esta pieza en el estudio que desarrollamos radica en que en la zona del pie, concretamente en su parte externa, apareció decorada con pintura. Tenemos varios trazos lineales en pintura blanca que se completan con un elemento fitomorfo esquematizado. En la Península Ibérica se han encontrado ejemplares de sigillata hispánica policromados, decorados a buril, o bien combinando ambas técnicas como un ejemplar de Numancia (Romero Carnicero 1985: 244, $\mathrm{n}^{\circ}$ 916). Como bien apunta su investigadora, la primera técnica no es algo novedosa, así está bien atestiguada la aplicación de barbotinas blancas y/o amarillas en Andújar (Roca 1976: 89-90, lám. 34) o más claras para Bezares y Arenzana (Garabito 1978: 225 y 460-461, fig. 49/lám. 44, no 3 y fig. 111/lám. 96, nº 7). El hecho de que el aparecido en Numancia tenga un acabado bícromo -negro y blanco- lo hace aún más interesante (Romero Carnicero 1985: 244, no 196). En el ejemplo de Arenzana de Arriba tenemos un posible sigillum decorativo con pigmento negro perdido del que solo se aprecia la impronta (Garabito 1978: 460-461, fig. 111, $\mathrm{n}^{\circ} 7$, lám. 96) pero que tendría una funcionalidad más epigráfica-epónima que decorativa, tal y como vemos en nuestro ejemplar. Este abundante repertorio cromático alternable con piezas sin decoración podría haber sido la expresión de un fenómeno decorativo que no afectó a todas las zonas por igual, y que incluso puede responder a deseos decorativos post-compra, siendo por lo tanto una corriente decorativa más cercana al deseo individual de imprimirle a estas piezas un marcado carácter étnico celtíbero. De ahí que la consideremos dentro del repertorio de la cerámica pintada local más que foránea.

Buscando otros paralelos, si volvemos la vista a La Graufesenque encontramos dos claros ejemplos, el primero de ellos es la inscripción CALVS con pigmentos ocres y ubicada en la parte inferior de un busto masculino no identificado -atribuido por algunos al 


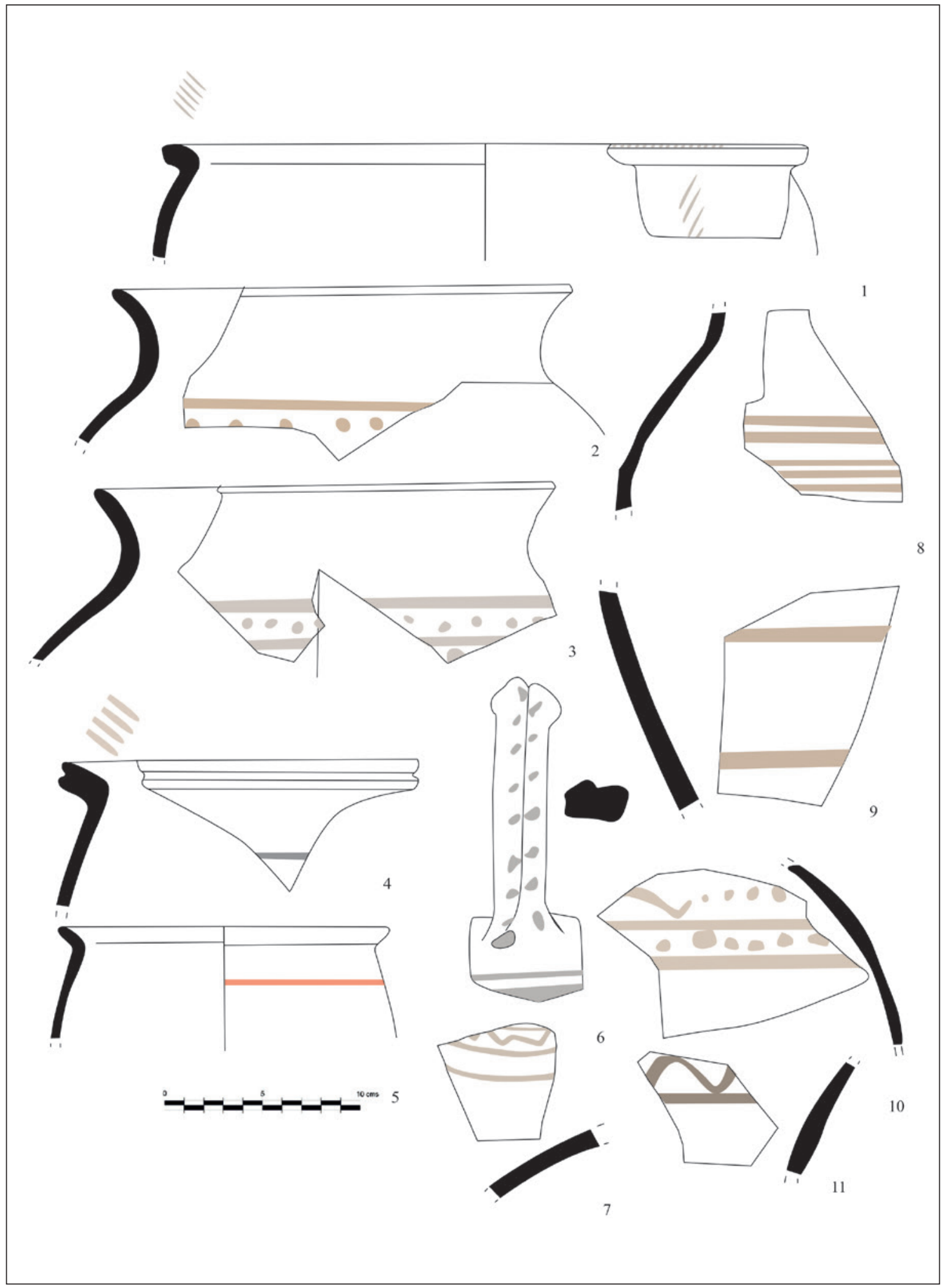

Figura 10. Piezas pintadas de producción emeritense (a partir de Abascal 1986). 


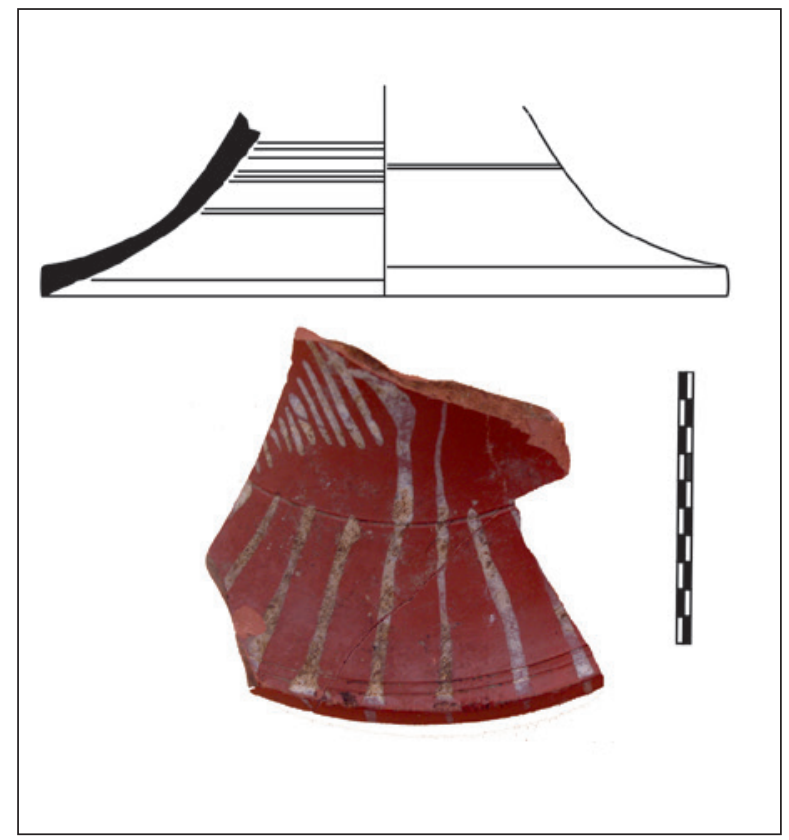

Figura 11. Pie de forma Hisp. 94 con decoración pintada (a partir de Bustamante 2013: lám. 169). emperador Calígula- (Genin ed. 2007: 243, fig. 378); y también hay otros ejemplos de decoración en blanco de carácter geométrico en un plato Drag. 15/17 ruteno (Genin ed. 2007: 256, fig. 393), así como restos de inscripciones posiblemente de cuentas efectuadas también en platos Drag. 15/17 (Genin ed. 2007: 256, fig. 392).

\section{CONCLUSIONES}

Con esta aportación, hemos querido iniciar una línea de investigación sobre una producción que, aunque no muy abundante, sí parece tener un hueco en los primeros siglos del imperio. De todas las piezas estudiadas que alcanzan la centena, predominan los ejemplares localizados en Cáparra, siguiéndoles de cerca los hallados en Mérida. Podemos calificar el fenómeno del consumo de las pintadas como urbano, siendo la aparición en el mundo rural muy escueta.

Del total de las piezas localizadas el 57\% corresponden al grupo Meseta Sur, le siguen las piezas emeritenses con un 28 ' $15 \%$ y muy lejos de estos números

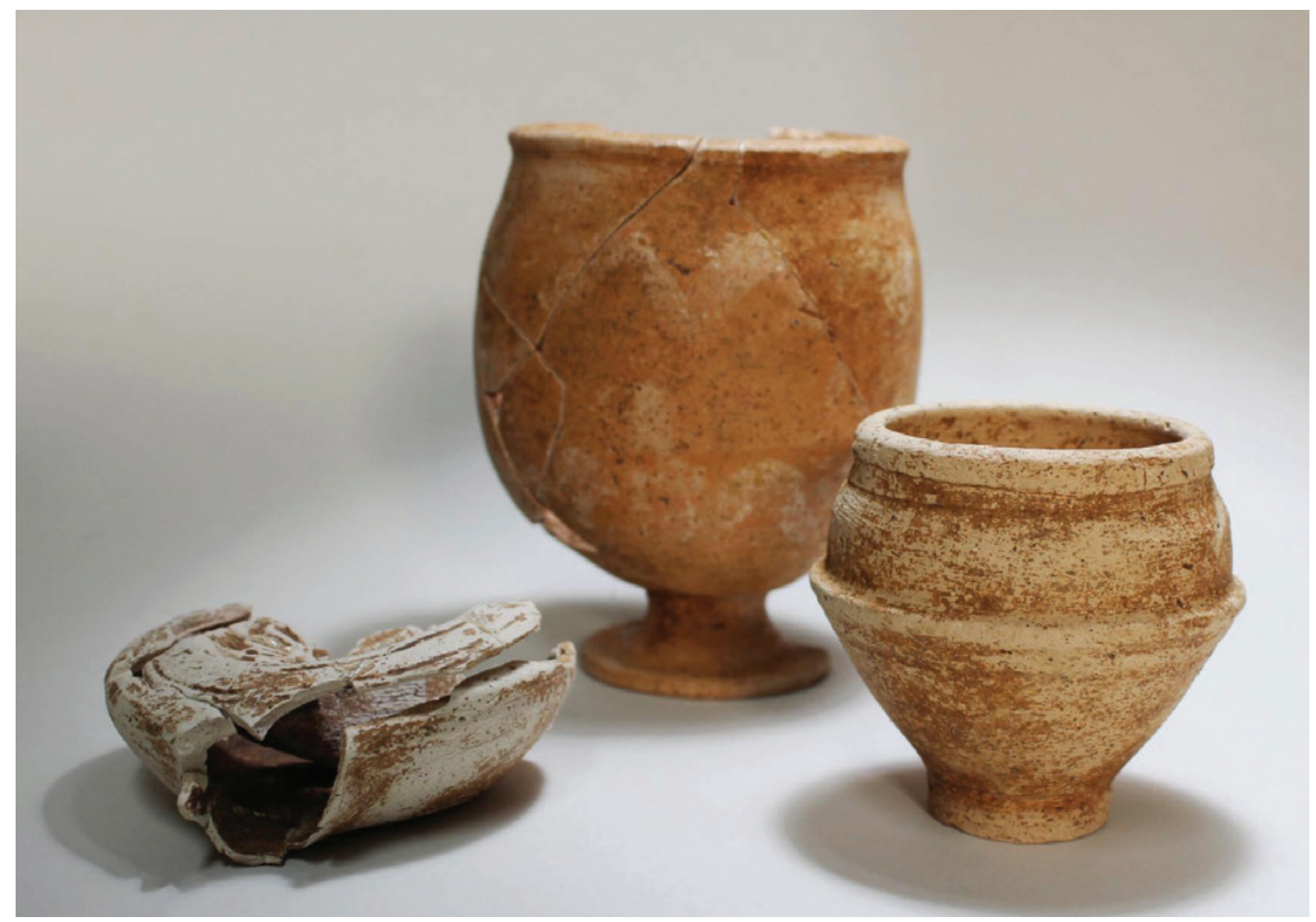

Figura 12. Contexto funerario con cáliz pintado procedente de Mérida (Méndez 2006: fig. 21). 


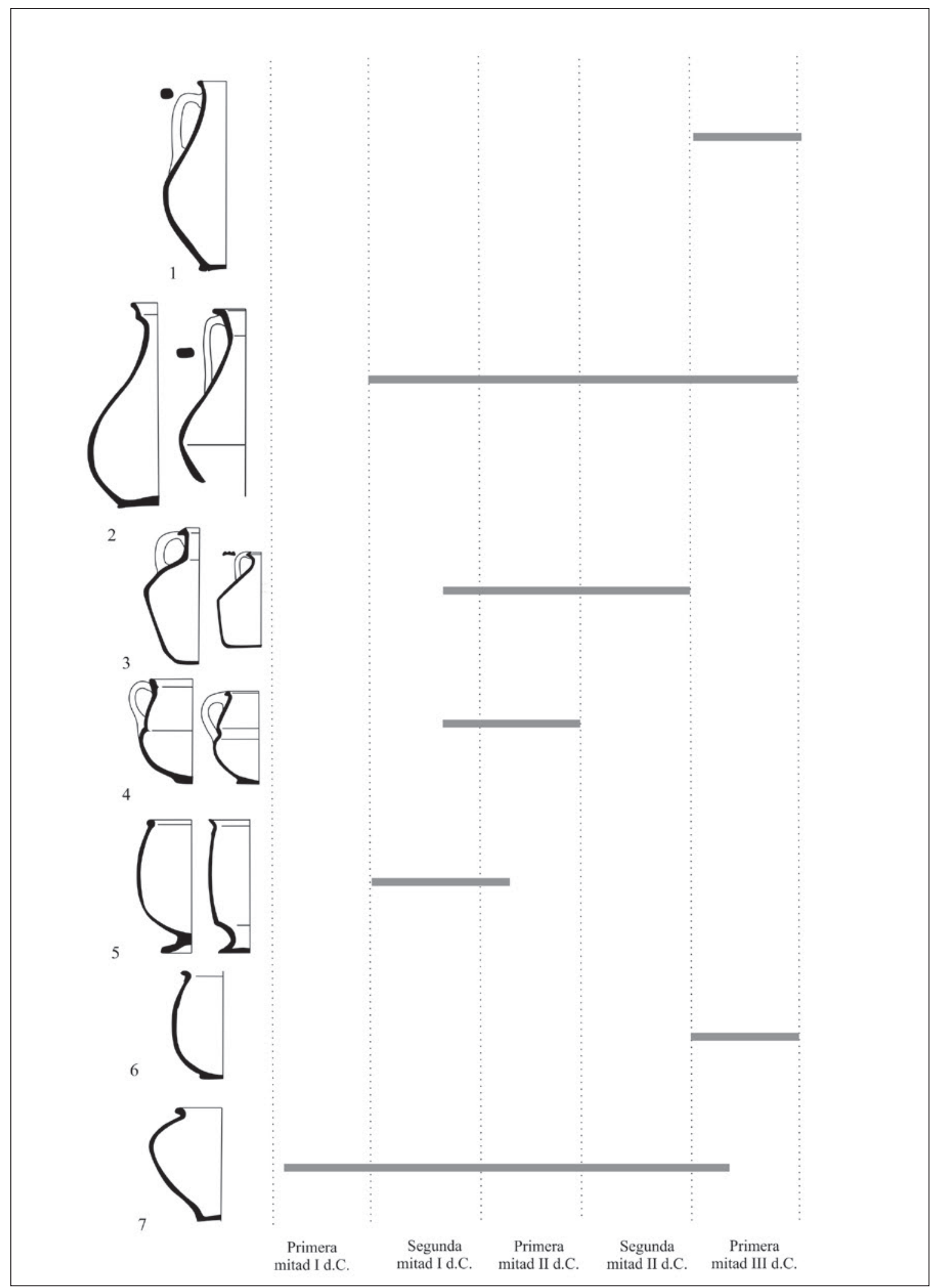

Figura 13. Esquema cronológico de los principales tipos pintados localizados en Augusta Emerita. 
estarían las caparenses (6'7\%) y las de la Meseta Norte $(7,7 \%)$.

En líneas generales, hemos podido aislar piezas procedentes de la Meseta que, sobre todo, se focalizan en el yacimiento de Cáparra, en la segunda mitad del I d.C. y en Mérida donde se repite el arco cronológico.

El grupo predominante son las piezas de la Meseta Sur con decoraciones y cromatismo muy reiterativo. Al respecto las escaleras invertidas, los trazos lineales y los elementos florales son los motivos más repetidos. A priori, casi todas las piezas podemos caracterizarlas como foráneas, aunque Abascal (1986: 101), para algunos casos concretos, habló de talleres locales.

En relación a los tipos, el más sobresaliente es la forma 17 , a modo de pequeña olla con decoración abigarrada en su zona superior. La aparición en Extremadura es amplia en el Norte siendo Cáparra y Augustobriga los dos núcleos receptores por antonomasia. En Mérida aparece también pero en un número muy reducido.

El segundo grupo en aparición sería el de la Meseta Norte -comúnmente denominado como tipo Clunia- el cual, de nuevo, se focaliza en Cáparra. Un único ejemplar ha sido localizado en Mérida, el cual se incluye cronológicamente en época flavia gracias a su contexto.

El tercer y cuarto grupos pueden caracterizase como los puramente locales. En este caso hemos aislado dos focos productivos, uno al norte -en Cáparra y su entorno-y otro al sur -en Mérida-. Cronológicamente el primero parece adscribirse a fines del siglo I d.C., con una decoración y con unas formas que se acercan mucho a las tradiciones indígenas locales. Frente a lo que podemos ver en las pintadas emeritenses, esta técnica no perdura cronológicamente en el tiempo. La reiteración de formas y esquemas decorativos es un elemento indiscutible para calificar al complejo como de taller.

En relación al foco de Mérida, su definición es más compleja. No hablamos de un taller propiamente dicho, sino de actuaciones puntuales y aleatorias que no permiten aislar un centro productor. Únicamente hemos sido capaces de aislar una posible mano que alterna líneas simples y cenefas punteadas y que, en una de sus posibles creaciones, plasma caracteres griegos (fig. 8, $\mathrm{n}^{\mathrm{o}} 4,7$ o fig. $9, \mathrm{n}^{\mathrm{o}} 2$ ).

La escasez de los hallazgos no nos permite hablar de un fuerte impacto de estas en los circuitos comerciales. De hecho las piezas localizadas y producidas se focalizan en la segunda mitad del I d.C., momento de máxima eclosión del taller emeritense $\mathrm{y}$, por consiguiente, son piezas que no fueron manufacturadas para suplir ningún tipo de carencia comercial. Para Mérida las sigillatas hispánicas fueron las predominantes pero les siguieron muy de cerca las paredes finas locales hasta, al menos, mitad del II d.C., momento en el cual estas ven caer su producción. Este panorama se aleja mucho del que se percibe en otras ciudades, caso de Complutum (Polo 1995: 100) donde las pintadas superan numéricamente a las paredes finas pero quedan muy atrás de las sigillata hispánicas.

Frente a lo que vemos en Cáparra, el uso de técnica pintada parece prolongarse hasta el siglo $\mathrm{V} \mathrm{d}$.C. aunque no es objeto de estudio en este trabajo.

\section{Agradecimientos}

Agradecemos los datos aportados por Dña. Ana M. Bejarano y Dña. M. Eulalia Gijón en relación con el registro de la ciudad hispanorromana de Cáparra. Al Consorcio de Mérida por el permiso otorgado para estudiar la cerámica del solar de la calle Almendralejo 41 (permiso de uso 2011/478) y a los directores de dicha intervención D. Javier Heras y Dña. Ana Olmedo. Para finalizar, al MNAR, especialmente a D. Rafael Sabio así como D. Agustín Velázquez por las facilidades brindadas para el estudio.

\section{BIBLIOGRAFÍA}

Abascal Palazón, J.M. (1986): La cerámica pintada romana de tradición indigena en la Península Ibérica. Madrid, Universidad de Alicante.

Abascal Palazón, J. M. (2008): "Las cerámicas “Tipo Clunia" y otras producciones pintadas hispanorromanas", en D. Bernal y A. Ribera (coords.), Cerámicas hispanorromanas. Un estado de la cuestión: 429-444. Cádiz, Universidad de Cádiz.

Álvarez Sáenz de Buruaga, J. (1956): "Museo Arqueológico de Mérida (Badajoz)". Memorias de los Museos Arqueológicos Provinciales 1952-1953: 2-11, Madrid, Junta Superior.

Aquilué Abadías, X. y Bello Rodrigo, J.R. (2009): "Materiales arqueológicos de los contextos constructivos y de amortización", en R. Ayerbe, T. Barrientos y F. Palma, El foro de Augusta Emerita génesis y evolución de sus recintos. Anejos de AEspA, LIII. Mérida, CSIC.

Bustamante Álvarez, M. (2011): La cerámica altoimperial en Augusta Emerita: entre el comercio y la exportación. Serie Ataecina 7. Mérida, Asamblea de Extremadura. 
Bustamante Álvarez, M. (2012): “La cerámica común altoimperial de Augusta Emerita", en D. Bernal y A. Ribera (coords.), Cerámicas hispanorromanas. Un estado de la cuestión: 407-433. Cádiz, Universidad de Cádiz.

Bustamante Álvarez, M. (2013): La terra sigillata hispánica en Augusta Emerita. Estudio tipocronológico a partir de los vertederos del suburbio norte. Anejos de Archivo Español de Arqueología LXV. Mérida, CSIC.

Bustamante Álvarez, M.; Bejarano, A. y Cerrillo Martín de Cáceres, E. (2014): "Evidencias de una figlina en el municipio hispanorromano de Caparra (Cáceres)", en R. Morais, A. Fernández y M. J. Sousa, As produções cerámicas de imitação na Hispania, Monografias ex Officina Hispana II: 341-348. Oporto, Museo de Arqueología de Braga (Portugal).

Bustamante Álvarez, M. y Heras Mora, F.J. (2013): "Producción anfórica en Augusta Emerita (Mérida, Badajoz) y los nuevos hallazgos del solar de la Escuela de Hostelería”, en D. Bernal, L.C. Juan, M. Bustamante, J.J. Díaz y A.M. Sáez (eds.), Hornos, talleres y focos de producción alfarera en Hispania, I Congreso Internacional de la SECAH Ex officina hispana. Monografías de la Sociedad de Estudios de la Cerámica Antigua en Hispania I: 239-253. Cádiz (2011), Cádiz, Universidad de Cádiz.

Garabito, T. (1978): Los alfares romanos riojanos. Producción y comercialización. Bibliotheca Praehistorica Hispana XVI. Madrid, CSIC.

García Merino, C.; Sánchez Simón, M. y Burón Álvarez, M. (2009): “Cultura material del siglo III en un ambiente doméstico de la Meseta: el conjunto cerrado de la Casa de los Plintos de Uxama". Archivo Español de Arqueología 82: 221-253

Genin, M. (ed.) (2007): La Graufesenque (Millau, Aveyron). II. Sigillées lisses et autres productions. Talence, Aquitania.

Luezas, A. y Martín-Bueno, M. (1995): “Cerámica pintada romana de tradición indígena procedente de Bilbilis (Calatayud, Zaragoza)". Espacio, Tiempo y Forma, Serie I, Prehistoria y Arqueología 8: 235-293.

Mayet, F. (1975): Les céramiques à parois fines dans la Péninsule Ibérique. París, Boccard.

Méndez Grande, G. (2006): "Desarrollo de un espacio agropecuario funerario en la zona sur de la ciudad. Intervención arqueológica realizada ente las c/Tomás Romero de Castilla y Antonio Hernández Gil
(Mérida)". Mérida. Excavaciones arqueológicas 2003, Memoria 9: 313-356. Mérida, Consorcio de Mérida.

Picado Pérez, Y. (2006): "Restos funerarios en torno a una vía de acceso a Emerita Augusta en la zona norte de Mérida. Intervención arqueológica realizada en el solar n 51 de la Avenida de Extremadura (Mérida)", Mérida. Excavaciones arqueológicas 2003, Memoria 9: 91-108. Mérida, Consorcio de Mérida.

Polo, J. (1999): “Las cerámicas pintadas romanas de tradición indígena: aportaciones estratigráficas de la ciudad hispano romana de Complutum", en II Congreso de Arqueología Peninsular: 89-102. Zamora (1996), Zamora, Fundación Rei Afonso Henriques.

Río-Miranda Alcón, J. (2012): La ciudad romana de Cáparra: la cerámica. Pamplona.

Roca Roumens, M. (1976): Sigillata Hispánica producida en Andújar (Jaén). Jaén, Instituto de Estudios Giennenses, Excma. Diputación Provincial.

Rodríguez Díaz, A. (1995): “Territorio y etnias prerromanas en el Guadiana medio: aproximación arqueológica a la Baeturia Túrdula", en Celtas y túrdulos: la Beturia: 205-254. Mérida, Museo Nacional de Arte Romano.

Romero Carnicero, M. V. (1985): Numancia I. La terra sigillata. Madrid, Excavaciones Arqueológicas en España.

Ruiz Valderas, E. (1988): “Cerámica pintada de tradición indígena en la Cartagena Romana". Arte y poblamiento en el S.E. peninsular. Antigüedad y cristianismo V: 621.

Sabio, R. y Bustamante, M. (2014): "Copa de cerámica", en Catálogo de la exposición Ars Scribendis: 60. Madrid, Ministerio de Cultura. http:// es.calameo.com/books/000075335b1e4ece31c76

Sánchez y Sánchez, M.A. (1992): Cerámica común romana de Mérida. Series de Arqueología Extremeña $\mathrm{n}^{\circ}$ 3. Cáceres.

Sánchez y Sánchez, M.A. (1995): "Producciones importadas en la vajilla culinaria del Bajo Guadalquivir", en Ceràmica comú romana d'época Alto-Imperial a la Península Ibèrica. Estat de la qüestió: 251-279. Barcelona, Universidad de Barcelona.

Sánchez Simón, M. (1995): “Notas sobre la cerámica pintada de tradición indígena a comienzos de la época flavia en Uxama (Osma, Soria)". Boletín del Seminario de Estudios de Arte y Arqueología 61: 125-144.

Taracena, B. (1931-32): "La cerámica de Clunia". Archivo Prehistoria Madrileña, II-III, 85-91. 